Linköping Studies in Science and Technology

Dissertation No. 1878

\title{
Defect-engineered (Ti,Al)N thin films
}

\author{
Isabella Citlalli Schramm Benítez
}

\section{LINKÖPING \\ UNIVERSITY}

Nanostructured Materials

Department of Physics, Chemistry and Biology (IFM)

Linköping University, Sweden

Part of

Joint European Doctoral program in Materials Science and Engineering (DocMASE) in collaboration with Chair of Functional Materials, Saarland University, Germany 
(C) Isabella Citlalli Schramm Benítez, unless otherwise stated ISBN: 978-91-7685-456-3 ISSN: 0345-7524

Printed by LiU-Tryck, Linköping, Sweden, 2017 
Dedicado a mi Familia 


\begin{abstract}
This thesis investigates the effect of point defects (nitrogen vacancies and interstitials) and multilayering $((\mathrm{Ti}, \mathrm{Al}) \mathrm{N} / \mathrm{TiN})$ on the phase transformations in cathodic arc-evaporated cubic $(\mathrm{Ti}, \mathrm{Al}) \mathrm{N}$ thin films at elevated temperatures. Special attention is paid to the evolution of the beneficial spinodal decomposition into $c$-TiN and $c$-AlN, the detrimental formation of wurtzite AIN and the potential application as hard coating in cutting tools.

$c-\left(\mathrm{Ti}_{1-\mathrm{x}} \mathrm{Al}_{\mathrm{x}}\right) \mathrm{N}_{\mathrm{y}}$ thin films with varying $\mathrm{Al}$ fractions and $\mathrm{N}$ content $(\mathrm{y}=0.93$ to 0.75$)$ show a delay in the spinodal decomposition when increasing the amount of $\mathrm{N}$ vacancies. This results in a $300{ }^{\circ} \mathrm{C}$ upshift in the age hardening and a delay in the $w$-AlN formation, while additions of self-interstitials enhance phase separation. High temperature interaction between hard metal substrates and thin films is more pronounced when increasing $\mathrm{N}$ deficiency through diffusion of substrate elements into the film. Low $\mathrm{N}$ content films ( $y=0.58$ to 0.40 ) showed formation of additional phases such as $\mathrm{Ti}_{4} \mathrm{AlN}_{3}$, $\mathrm{Ti}_{2} \mathrm{AlN}, \mathrm{Al}_{5} \mathrm{Ti}_{2}$ and $\mathrm{Al}_{3} \mathrm{Ti}$ during annealing and a transformation from $\mathrm{Ti}_{2} \mathrm{AlN}$ to $\mathrm{Ti}_{4} \mathrm{AlN}_{3}$ via intercalation. The multilayer structure of TiN/TiAlN results in surfacedirected spinodal decomposition that affects the decomposition behavior. Careful use of these effects appears as a promising method to improve cutting tool performance.
\end{abstract}




\section{Zusammenfassung}

Diese Arbeit untersucht den Effekt von Punktdefekten (Stickstoffleerstellen und Zwischengitteratome) und Multilagen $((\mathrm{Ti}, \mathrm{Al}) \mathrm{N} / \mathrm{TiN})$ auf die Phasenumwandlung in lichtbogenverdampften kubischen (Ti,Al)N-Dünnschichten bei erhöhten Temperaturen. Besonderes Augenmerk liegt auf der Entwicklung der vorteilhaften spinodalen Entmischung in $c$-TiN und $c$-AlN und der nachteiligen Bildung von Wurtzit-AlN, sowie der möglichen Anwendung als Hartstoffbeschichtung von Schneidwerkzeugen.

$c-\left(\mathrm{Ti}_{1-\mathrm{x}} \mathrm{Al}_{\mathrm{x}}\right) \mathrm{N}_{\mathrm{y}}$ mit unterschiedlichem $\mathrm{Al}$-Anteil und $\mathrm{N}-$ Gehalten von $\mathrm{y}=0,93$ bis 0,75 zeigt mit zunehmenden Stickstoffleerstellen eine Verzögerung der spinodalen Entmischung. Dadurch verschiebt sich die Ausscheidungshärtung um $300{ }^{\circ} \mathrm{C} z u$ höheren Temperaturen und die $w$-AlN-Bildung wird verzögert, während der Einbau von Eigenzwischengitteratomen die Entmischung beschleunigt. Die Hochtemperaturwechselwirkung zwischen Hartmetallsubstrat und Dünnschicht durch Diffusion von Substratelementen in die Schicht nimmt mit steigendem Stickstoffdefizit zu. Stickstoffarme Schichten $(\mathrm{y}=0,58$ bis 0,40$)$ zeigen während der Wärmebehandlung zusätzliche Phasen wie $\mathrm{Ti}_{4} \mathrm{AlN}_{3}, \mathrm{Ti}_{2} \mathrm{AlN}, \mathrm{Al}_{5} \mathrm{Ti}_{2}$ und $\mathrm{Al}_{3} \mathrm{Ti}$ und eine Umwandlung von $\mathrm{Ti}_{2} \mathrm{AlN}$ in $\mathrm{Ti}_{4} \mathrm{AlN}_{3}$ durch Interkalation. Die Multischichtstruktur von TiN/TiAlN führt

$\mathrm{zu}$ einer oberflächengerichteten spinodalen Entmischung, die das Entmischungsverhalten beeinflusst. Ein gezielter Einsatz dieser Effekte erscheint als ein vielsprechender Weg, um die Leistungsfähigkeit von Schneidwerkzeugen zu verbessern. 


\section{Sammanfattning}

I denna avhandling behandlas inverkan av punktdefekter (kvävevakanser och interstitialer) och multilagring $((\mathrm{Ti}, \mathrm{Al}) \mathrm{N} / \mathrm{TiN})$ på högtemperaturfasomvandlingar $\mathrm{i}$ tunna arcförångade skikt av kubiska (Ti,Al)N. Störst vikt har lagts på utvecklingen av det fördelaktiga spinodala sönderfallet till c-TiN och c-AlN, den ofördelaktiga omvandlingen till w-AlN och potentialen som hårda skikt i verktygstillämpningar.

Tunna $c-\left(\mathrm{Ti}_{1-\mathrm{x}} \mathrm{Al}_{\mathrm{x}}\right) \mathrm{N}_{\mathrm{y}}$ skikt med olika Al-andel och en $\mathrm{N}$-halt mellan $(\mathrm{y}=0.93$ och 0.75$)$ uppvisar ökad undertryckning av det spinodala sönderfallet med ökat kvävevakanshalt. Detta resulterar i bildandet av w-AlN skiftas upp i temperatur vilket gör att åldershärdningen höjs med $300{ }^{\circ} \mathrm{C}$. Däremot medför närvaron av självinterstitialer ett snabbare sönderfall. Växelverkan mellan hårdmetallsubstraten och de tunna skikten vid hög temperatur ökar med minskad kvävehalt i skiten genom diffusion av atomer från substratet in i filmen. Filmer med låg kvävehalt $(\mathrm{y}=0.58$ till 0.40$)$ bildar även andra faser så som $\mathrm{Ti}_{4} \mathrm{AlN}_{3}, \mathrm{Ti}_{2} \mathrm{AlN}, \mathrm{Al}_{5} \mathrm{Ti}_{2}$ och $\mathrm{Al}_{3} \mathrm{Ti}$ under värmebehandling och fasomvandlingen från $\mathrm{Ti}_{2} \mathrm{AlN}$ till $\mathrm{Ti}_{4} \mathrm{AlN}_{3}$ sker via en mekanism kallad intercalation. Multilagring av TiN/TiAlN resulterar i ett ytriktad spinodalt sönderfall vilket påverkar det totala sönderfallsförloppet. Nyttjande av dessa resultat syns som lovande vägar till förbättrade verktygsegenskaper. 


\section{Populärvetenskaplig sammanfattning}

En tunnfilm är ett tunt lager av ett material som oftast täcker ett större objekt av ett annat material. Att man belägger ett objekt beror på att man vill förbättra, förändra eller skydda ytan av objektet, t.ex. för att göra ytan mer motståndskraftig mot repor eller värme, filtrera UV-ljus, vara vattenavvisande, eller helt enkelt ändra dess färg. Enligt litteraturen kan en tunnfilmens tjocklek kan variera från ett atomlager till flera mikrometer. Man måste klyva ett hårstrå på längden i flera hundra delar för att få samma tjocklek. Det intressanta med dessa beläggningar är att trots att det är så tunna så kan de ge stora förändringar på objekt som är betydligt större, t. ex. något om vi kan hålla i handen.

De tunna filmer som är studerade i denna avhandling har potential att användas på verktyg för metallbearbetning. När man svarvar eller fräser arbetsstycken av metall så gör med det med en relativt hög skärhastighet, vilket medför att verktyget utsätts för hög temperatur och högt tryck. Trots dessa betingelser så måste verktyget vara hårt för att skärprocessen skall fungera. Ett vanligt förekommande tunnfilmsmaterial inom verktygsindustrin är titanaluminiumnitrid som också kan skrivas som (Ti,Al)N. I denna avhandling har detta material används som utgångspunkt och sedan förändrats för att göra det ännu bättre. En viktig egenskap som (Ti,Al)N har är att det vid höga temperaturer bildar som domäner av titannitrid TiN och aluminiumnitrid AlN som gör att tunnfilmen kan bibehålla sin höga hårdhet men om temperaturen blir för hög så tappar ändå materialet sin hårdhet.

I denna avhandling så har i huvudsak två saker ändrats hos (Ti,Al)N för att förbättra egenskaperna och trycka upp den negativa fasomvandlingen till ännu högre temperaturer. I den första delen så undersöktes effekten av att minska kvävehalten i (Ti,Al)N utan att förändra kristallstrukturen men en del av kvävepositionerna var tomma. I denna andra delen användes $(\mathrm{Ti}, \mathrm{Al}) \mathrm{N}$ som en del i en multilagerstruktur tillsammans med TiN och sedan studerades multilagrets egenskaper. Resultaten visar 
att genom att ta bort en liten andel av kvävet så förbättras materialets hårdhet vid höga temperaturer och den negativa fasomvandlingen är fördröjd till högre temperaturer. Om man tar bort för mycket kväve så bildas nya faser och fasomvandlingar som gör att materialet inte längre lämpar sig som en ytbeläggning på verktyg. Slutsatsen är ändå att styrning av kväveinnehållet är en parameter som tidigare negligerats men som har stor potential att förbättra (TiAl)N-belagda verktygs egenskaper. Dessutom bör konceptet även undersökas hos andra nitridsystem. 


\section{Preface}

The work presented in this thesis is a result of my doctoral studies in the Erasmus Mundus joint doctoral program, DocMASE, at two research groups in two Universities between 2012 and 2017. Functional materials group at Saarland University (Saarbrücken, Germany) and Nanostructured materials group at Linköping University (Linköping, Sweden) in strong collaboration with SECO Tools (Fagersta, Sweden). In addition, the work was supported by the German Research Society (DFG), the federal state government of Saarland (Germany), the European Regional Development Fund (project AME-Lab), the Swedish Research Council (VR) and the Swedish Foundation for Strategic Research (SSF).

Isabella Citlalli Schramm Benítez

Linköping, 2017 


\section{Included papers and my contributions}

I. Impact of nitrogen vacancies on the high temperature behavior of $\left(T i_{1-x} A l_{x}\right) N_{y}$ alloys

I.C. Schramm, M.P. Johansson Jõesaar, J. Jensen, F. Mücklich and M. Odén Acta Materialia 119 (2016) 218

Carried out the major part in the planning and characterization, besides ERDA measurements, and wrote the first draft of the paper.

II. Solid state formation of $\mathrm{Ti}_{4} A l N_{3}$ in cathodic arc evaporated $\left(T i_{1-x} A l_{x}\right) N_{y}$ alloys

I.C. Schramm, C. Pauly, M.P. Johansson Jõesaar, P. Eklund, J. Schmauch, F. Mücklich, M. Odén

Acta Materialia 129 (2017) 268

Carried out the major part in the planning and characterization, besides TEM experiments where I participated, and wrote the first draft of the paper.

III. Effect of nitrogen vacancies on phase stability and mechanical properties of arc deposited $\left(\right.$ Ti $\left._{0.52} \mathrm{Al}_{0.48}\right) N_{y}(y<1)$ coatings

I.C. Schramm, C. Pauly, M.P. Johansson Jõesaar, S. Slawik, S. Suárez, F. Mücklich and M. Odén

Surface and Coatings Technology 330 (2017) 77

Carried out the major part in the planning and characterization, besides TEM and EBSD experiments where I participated, and wrote the first draft of the paper.

IV. Enhanced thermal stability and mechanical properties of nitrogen deficient titanium aluminum nitride (Ti0.54Al0.46 $N_{y}$ ) thin films by tuning the applied negative bias voltage

K.M. Calamba, I.C. Schramm, M.P. Johansson Jõesaar, J. Ghanbaja, J.F. Pierson, F. Mücklich and M. Odén

Journal of Applied Physics 122 (2017) 065301 
Took part in the experimental work, carried out the APT experiments and the SEM imaging, and contributed to the writing and discussion of the manuscript.

V. $\quad$ Surface directed spinodal decomposition at TiAlN/TiN interfaces

A. Knutsson, I.C. Schramm, K. Asp Grönhagen, F. Mücklich and M. Odén Journal of Applied Physics 113 (2013) 114305

Took part in the experimental work, carried out the APT experiments, and contributed to the writing and discussion of the paper. 


\section{Related papers but not included in the thesis}

VI. Nanostructured and coherency strain in multicomponent hard coatings

R. Forsén, I.C. Schramm, P.O.Å. Persson, F. Mücklich, M. Odén and N. Ghafoor

Applied Physics Letters. Materials 2 (2014) 116104

VII. Tuning hardness and fracture resistance of $\mathrm{ZrN} / \mathrm{ZrAlN}$ nanoscale multilayers by stress-induced transformation toughening.

K. Yalamanchili, I.C. Schramm, E. Jiménez-Piqué, L. Rogström, F. Mücklich, M. Odén and N. Ghafoor

Acta Materialia 89 (2015) 22

VIII. Exploring the high entropy alloy concept in (AlTiVNbCr)N

K. Yalamanchili, F. Wang, I.C. Schramm, J. Andersson, M.P. Johansson Jõesaar, F. Tasnadi, F. Mücklich, N. Ghafoor and M. Odén

Thin Solid Films 636 (2017) 346

IX. Thermal and mechanical stability of wurtzite-ZrAlN/cubic-TiN and wurtziteZrAlN/cubic-ZrN multilayers

Y.H. Chen, L. Rogström, J.J. Roa, J.Q. Zhu, I.C. Schramm, L.J.S. Johnson, N. Schell, F. Mücklich, M.J. Anglada and M. Odén

Surface and Coatings Technology 324 (2017) 328

X. A coated cutting tool and a method for coating the cutting tool. Nitrogen deficient TiAlN

I.C. Schramm, M.P. Johansson Jõesaar and M. Odén

International Publication number: WO2016169935 


\section{Acknowledgements}

Professor Frank Mücklich, my supervisor at UdS. Thank you for giving me the opportunity of being part of your research group and for letting me work with advance techniques, such as atom probe. I have learned so much during this study.

Professor Magnus Odén, my supervisor at LiU. Thank you for all the guidance and support even if most of the times it was from far away, and for the opportunity of researching in a very interesting field, i.e. nitrides.

Dr. Sven Ulrich. I would like to thank you for the acceptance of the revision of this work and being my opponent at the Swedish committee.

Erasmus mundus joint doctoral program. My special gratitude goes to DocMASE program and the funding from Erasmus Mundus that made possible my $\mathrm{PhD}$ studies and such wonderful international research experience. Special thanks to Flavio Soldera.

Dr. Mats Johansson. Special thanks to you, without your collaboration this thesis would not have been possible. Thank you for all the interesting discussions and support along this thesis, and of course all the samples.

Christoph Pauly. My dear office mate, sharing office for many years is not a long time if one compares it to our life time. Nevertheless, it was a whole PhD student life time. Thank you so much for all the talks, support, patience, collaboration, discussions and, of course, all the M\&M's you gave me.

Collaborators. Thank you for your great contributions to my manuscripts and letting me be part of your projects, for the time spend doing experiments, and for all the interesting discussions. Axel, Björn, Christoph, Jens, Jörg, Katherine, Klara, Kumar, Lina, Mats, Michael, Naureen, Per, Peter, Rikard, Seba, Sebi and my supervisors.

Proof readers: Bea, Christoph, Faadhil, Lourdes, Magnus, Nico, Robin. Special thanks to you, I am sure my thesis would look much different without your precious help.

Therese Dannetun. Thank you so much for helping me in the administrative part and organization of many (all) of my LiU visits.

Functional materials group, Saarland University. I would like sincerely thank for making my work stay very nice and comfortable. Special thanks to Björn, Christoph and Sebi for all the talks, lunch breaks, fun and time spend together. 
Nanostructured Materials group, Linköping University. Even though I only spent short periods of time at Linköping, I felt part of the group and very welcome. Special thank for making my stay so fun and cool, Aylin and Fei.

Fika group, Linköping, Sweden. Unforgettable coffee breaks, and since then, I have learned to drink coffee without sugar and milk. Thanks for all the talks about everything and nothing, it was very helpful for keeping a clear mind.

Friends. To all my friends who are spread over the world and who are part of all kind of research groups and fields. I would like sincerely to thank you for filling my life with joy and happiness (sometimes with a bit of drama too). Especially to Alex, Anna, Aylin, Bea, Carole, Corinna, Fei, Jorge, Juan Manuel, Marie, Matthäus, Mayrena, Nati, Naty, Nuria, Violeta and Will.

Family. Last but not least, I especially would like wholeheartedly to thank my family (in Mexico and in Germany) for supporting me throughout all my decisions and in my path of life. Sé que no has sido fácil tenerme tan lejos de ustedes, tampoco lo has sido para mí. Sin embargo, he aprendido a llevar mi hogar y las personas que amo en mi corazón. Vielen Dank, dass ihr immer für mich da wart, für die Unterstützung bei allen meinen Umzügen und meinen Lebensentscheidungen. Y a las nenas, me gustaría incluirlas en mi familia, de todo mi corazón, gracias por acompañarme a lo largo de este camino por las Europas, los materiales y la vida. 


\section{Table of contents}

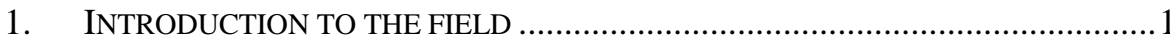

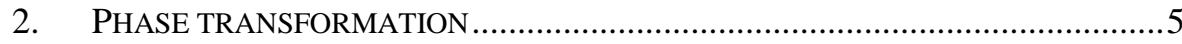

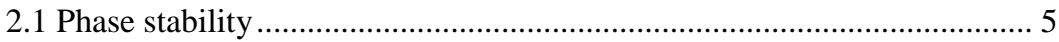

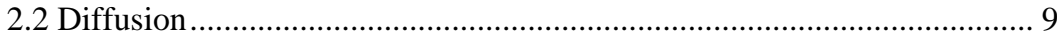

2.3 Diffusional transformations in solids .................................................. 10

2.3.1 Nucleation and growth .......................................................... 10

2.3.2 Spinodal decomposition and coarsening ................................ 12

2.3.3 Intercalation ....................................................................... 15

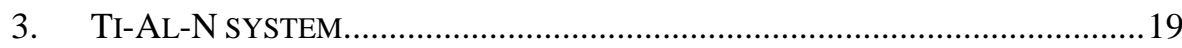

3.1 Stable phases in the Ti-Al-N system ............................................... 20

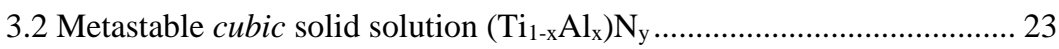

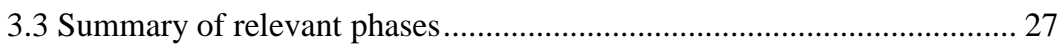

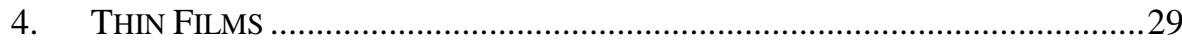

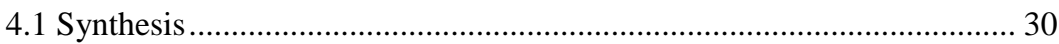

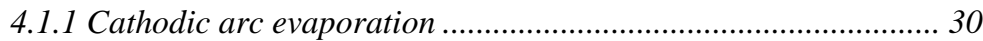

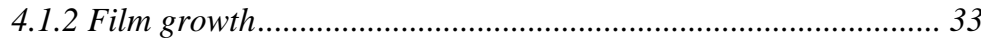

4.1.3 Experimental setup ................................................................ 35

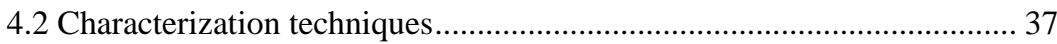

4.2.1 Differential scanning calorimetry ........................................... 37

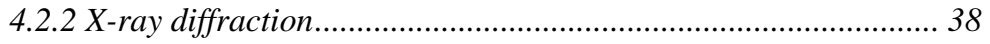

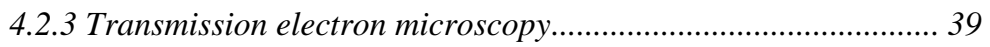


4.2.4 Scanning electron microscopy …........................................... 40

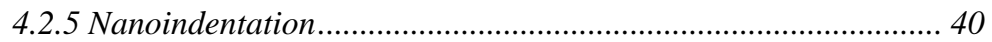

4.2.6 Elastic recoil detection analysis............................................. 41

4.3 Atom Probe Tomography ….............................................................. 42

4.3.1 Principle of operation ............................................................... 42

4.3.2 Limitations in APT .............................................................. 45

4.3.3 Sample preparation .................................................................. 47

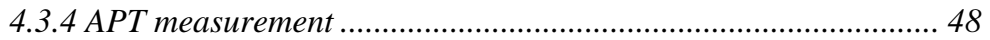

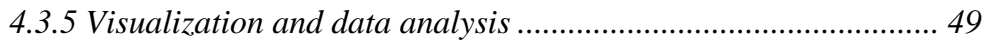

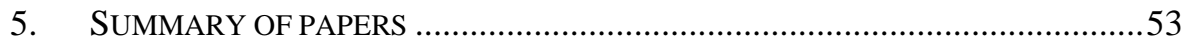

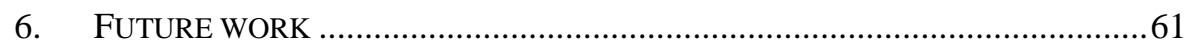

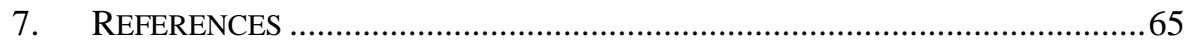

PAPER I

PAPER II

PAPER III

PAPER IV

PAPER V 


\title{
Acronyms and symbols
}

\author{
1D one-dimensional \\ 3D three-dimensional \\ APT atom probe tomography \\ c- $\quad$ cubic crystal structure \\ CVD chemical vapor deposition \\ Da Dalton \\ DSC differential scanning calorimeter \\ EBSD electron backscatter diffraction \\ EDS energy-dispersive X-ray spectroscopy \\ EFTEM filtered analytical transmission electron microscope \\ ERDA elastic recoil detection analysis \\ $F \quad$ evaporation field \\ fcc face-centered cubic \\ FDA frequency distribution analysis \\ FIB focused ion beam microscopy \\ G Gibbs free energy \\ HAADF high angle annular dark field STEM \\ HRTEM high-resolution TEM \\ Isosurface iso-concentration surface \\ $k_{f} \quad$ field factor \\ LEAP local-electrode atom probe \\ $\mu \quad$ Pearson coefficient \\ $m / q \quad$ mass-to-charge ratio \\ MAX $\quad M_{n+1} A_{n}$ \\ $\mathrm{N}_{\mathrm{v}} \quad$ nitrogen vacancies \\ Proxigram proximity histogram
}


PVD physical vapor deposition

ROI region of interest

SAD selected area diffraction

SDSD surface directed spinodal decomposition

SEM scanning electron microscopy

STEM scanning transmission electron microscopy

SZM structure zone model

TEM transmission electron microscopy

tflight time-of-flight

TG thermogravimetry

$\mathrm{T}_{\mathrm{m}} \quad$ melting point

TMN transition metal nitride

ToF-E time-of-flight energy

w- $\quad$ wurtzite crystal structure

XRD X-ray diffractometry 


\section{INTRODUCTION}

\section{TO THE FIELD}

Coated cutting tools constitute the majority of tools used nowadays in material removal with geometrically defined edges [1]. The cutting tool experiences an environment of high localized temperatures $\left(\sim 1000{ }^{\circ} \mathrm{C}\right)$ and high stresses $(\sim 700 \mathrm{MPa})$ during material removal [2], which makes metal machining a demanding process. It also encounters repeated impact loads (interrupted cuts) and interaction with the work piece chips. The use of a coating that withstands these harsh conditions has led to an improvement in tool lifetime and cutting performance. Ideally, this thin film should be chemically inert, stable at high-temperatures, wear resistant with low friction, oxidation resistant and harder than the substrate [2], [3]. There is a wide variety of hard coatings designed to meet the requirements of different applications on the market. Nevertheless, the appearance of new workpiece materials (difficult to cut) and the demand for higher production rates (extreme cutting conditions) lead to a strong, ongoing development in this field [1], [2], [4], [5]. In the scope of this thesis, the investigated films have the potential for their application as hard coatings for metal cutting in turning and milling tools.

TiN was the first commercial physical vapor deposited (PVD) coating used in the cutting tool industry in the late 70's, and since then, nitrides have governed most of the hard coating industry [1]. Among all available transition metal nitrides (TMNs) on the market, (Ti,Al)N is one of the most extensively investigated and used systems [1]-[3], [6]. It was the addition of $\mathrm{Al}$ into TiN which substantially improved its properties at elevated temperatures [7], [8]. Solid solution (Ti,Al)N coatings with a cubic (rock-salt) 
structure, typically deposited by PVD, exhibit high hardness ( $30 \mathrm{GPa})$, low thermal conductivity and good wear resistance [2], [3]. For medium to high Al content, a protective $\mathrm{Al}_{2} \mathrm{O}_{3}$ upper layer formed at high temperatures (above $700{ }^{\circ} \mathrm{C}$ ) is responsible for the good oxidation resistance [9], [10]. Furthermore, (Ti,Al)N coatings show high thermal stability and hot hardness [2], [3]. It is the evolution of hardness at elevated temperatures (age hardening) that is the key characteristic of these coatings.

The quasi-binary isostructural (rock-salt, B1) TiN-AlN phase diagram presents a miscibility gap [11], [12]. If a metastable solid solution cubic $(\mathrm{Ti}, \mathrm{Al}) \mathrm{N}$ is obtained inside the miscibility gap, the system will tend to phase separate into coherent $c$-TiN and $c$-AlN via spinodal decomposition instead of the thermodynamically stable phases $c$-TiN and $w$-AlN under the right conditions. The main advantage of spinodal decomposition is the formation of nanometer-sized $c$-TiN and $c$-AlN domains [3], [13][15]. The difference in elastic properties and lattice parameter between the different domains leads to coherency strain and a Koehler-type hardening [16]-[18], resulting in age hardening [16]. However, further annealing leads to coarsening of the domains, the formation of wurtzite AlN, and a degradation of mechanical properties, especially hardness [16], [19], [20]. Understanding and modifying the phase transformation in (Ti,Al)N has become a key factor to improve coating performance in the last three decades [3], [21], [22]. The use of other alloying elements, artificial layer structures, external pressure and stress are some of the proposed solutions for improving the thermal stability and suppressing the $w$-AlN formation [3], [23]-[27]. Although extensive research has been carried out on this system, there are few studies on the impact of point defects on the phase transformations in $(\mathrm{Ti}, \mathrm{Al}) \mathrm{N}$ thin films which is the main scope of this work.

This thesis investigates the unexplored effect of constitutional defects (nitrogen vacancies) and their combination with deposition-induced self-interstitials on the phase transformation of cubic solid solution $(\mathrm{Ti}, \mathrm{Al}) \mathrm{N}$ thin films at elevated temperatures. This was indirectly performed by reducing the nitrogen content of the as-deposited alloy and by applying a negative substrate bias voltage during film deposition in a cathodic arc 
evaporation system. Herein, point defect engineering is demonstrated to significantly impact the phase decomposition pathway, the evolution of microstructure and the hardness at elevated temperatures.

In addition, a deeper understanding of the effect of artificial interfaces in a multilayer configuration $(\mathrm{Ti}, \mathrm{Al}) \mathrm{N} / \mathrm{TiN}$ on the phase transformation on $(\mathrm{Ti}, \mathrm{Al}) \mathrm{N}$ was developed. Multilayering has been demonstrated to modify the phase transformation in a positive way [24]. Here, the internal interfaces are shown to shift the onset for decomposition to lower temperatures due to the appearance of surface-directed spinodal decomposition (SDSD).

The thesis is divided into two main parts. The first part is a background of the research that was carried out. Fundamental concepts are introduced, the employed characterization techniques are presented and the experimental setup is described. It concludes with an overview of the contribution made to the field by this work with a summary of the appended papers (manuscripts). The second part contains the result of the research in the form of scientific papers/manuscripts, which are briefly described below:

In Paper I, the effect of nitrogen vacancies on the thermal stability of cubic solid solution $\left(\mathrm{Ti}_{1-\mathrm{x}} \mathrm{Al}_{\mathrm{x}}\right) \mathrm{N}_{\mathrm{y}}$ free-standing coatings is presented for different $\mathrm{Al}$ metal ratios $(\mathrm{x}=0.26,0.48$ and 0.60$)$ and $\mathrm{N}$ deficiency from $\mathrm{y}=0.92$ to 0.75 .

In Paper II, highly $\mathrm{N}$ deficient $\left(\mathrm{Ti}_{1-\mathrm{x}} \mathrm{Al}_{\mathrm{x}}\right) \mathrm{N}_{\mathrm{y}}(0.58 \geq \mathrm{y} \geq 0.40)$ alloys are investigated for a wide range of $\mathrm{Al}$ metal fractions ( $\mathrm{x}=0.28$ to 0.63 ). The transformation path is presented and a transformation mechanism from $\mathrm{Ti}_{2} \mathrm{AlN}$ to $\mathrm{Ti}_{4} \mathrm{AlN}_{3}$ via intercalation is suggested.

In Paper III, substrate-coating interaction in the presence of $\mathrm{N}$ vacancies is investigated in $\left(\mathrm{Ti}_{0.52} \mathrm{Al}_{0.48}\right) \mathrm{N}_{\mathrm{y}}$ coatings. Commercial cemented carbides (WC/Co based) were used as substrate and the $\mathrm{N}$ deficiency ranged from $\mathrm{y}=0.92$ to 0.46 . 
In Paper $\boldsymbol{I} \boldsymbol{V}$, interaction and impact on thermal stability and mechanical properties when combining different types of point defects ( $\mathrm{N}$ vacancies and interstitials) in $\left(\mathrm{Ti}_{0.54} \mathrm{Al}_{0.46}\right) \mathrm{N}_{0.87}$ are presented.

In Paper $\boldsymbol{V}$, the effect of artificial interfaces on the thermal stability of $(\mathrm{Ti}, \mathrm{Al}) \mathrm{N}$ is investigated in a multilayer configuration $(\mathrm{Ti}, \mathrm{Al}) \mathrm{N} / \mathrm{TiN}$. Surface-directed spinodal decomposition is shown experimentally and confirmed by phase field simulations. 


\section{Phase transformation}

A phase transformation describes the change in a system from an initial state to a new one. The main driving force for this to occur is the minimization of the system's Gibbs free energy. Some examples of phase transformations are the transitions from solid, to liquid, to gaseous state by increasing the temperature; the change in crystal structure by applying pressure; the transition from ferromagnetic to paramagnetic states by crossing the Curie temperature, etc. In order to understand why a system wants to transform, to which state and how fast will it be, thermodynamics and kinetics are needed.

In this chapter, some thermodynamic concepts regarding the phase stability and the driving force for phase transformations in alloys are discussed, followed by a description of the main mechanism of transformation in this thesis: diffusion. Finally, for this thesis, three relevant diffusional transformations in solids are presented, i.e. nucleation and growth, spinodal decomposition and coarsening, and intercalation for MAX phase transformation.

\subsection{Phase stability}

A system is usually defined as a mixture of one or more phases; a phase, being a part of the system where the properties and composition are homogenous and physically different from other parts (phases) [28]. Every system is described by its Gibbs free energy:

$$
G=H-T S
$$


$\mathrm{H}$ is the enthalpy, $\mathrm{T}$ the temperature and $\mathrm{S}$ the entropy. Enthalpy represents the internal energy of the system and the entropy is related to its randomness.

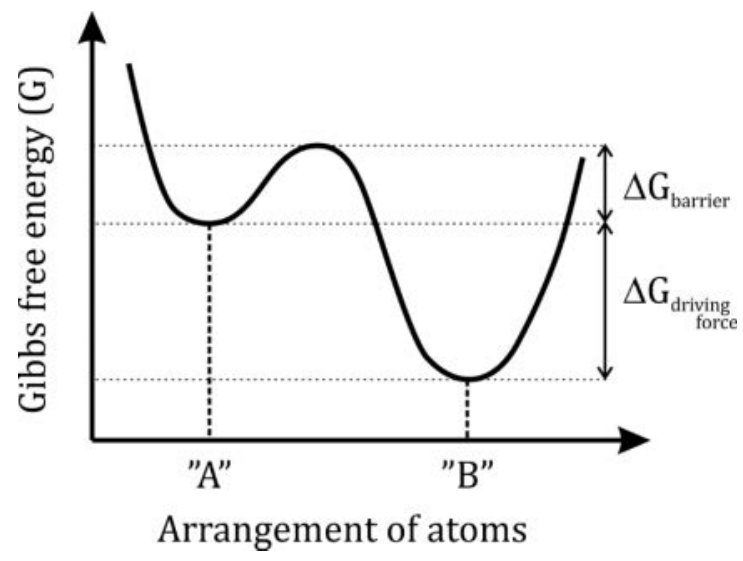

Figure 2.1: A schematic variation of Gibbs free energy with the arrangement of atoms. Configuration " $B$ " has the lowest free energy, were the system is at stable equilibrium. Configuration " $A$ " is a metastable state. Adapted from [28].

There are three main states of a system: stable, metastable or unstable. The equilibrium stable state is defined by the global minimum of the system's free energy, $\mathrm{dG}=0$, while a metastable state is any state where the energy is at a local minimum, $\mathrm{dG}=0$. Every other state where $\mathrm{dG} \neq 0$ is unstable. A simplified example of how the Gibbs free energy changes as a function of arrangement of atoms is shown in Figure 2.1. Two minimums are observed and only one, configuration "A", has the lowest free energy of the system, the equilibrium stable state [28]. The system is in thermodynamic equilibrium only when the Gibbs free energy is at its minimum, if this is not the case the system will have a natural tendency (driving force) to achieve the minimum energy. It is then when a phase transformation can take place.

A phase transformation does not necessarily occur straight to the equilibrium stable state, but can pass through intermediate metastable states, which may last for short or indefinite periods of time. The duration of any intermediate step will depend on the energy barrier ( $\left.\Delta \mathrm{G}_{\text {barrier }}\right)$ that the system must overcome to change state, e.g. free energy 
hump between configurations " $\mathrm{A}$ " and "B" (Figure 2.1). The higher $\Delta \mathrm{G}_{\text {barrier }}$ it is, the more difficult it will be for the system to change state. Of course, the duration of these metastable states also depends on other kinetic factors (which are further described in text below).

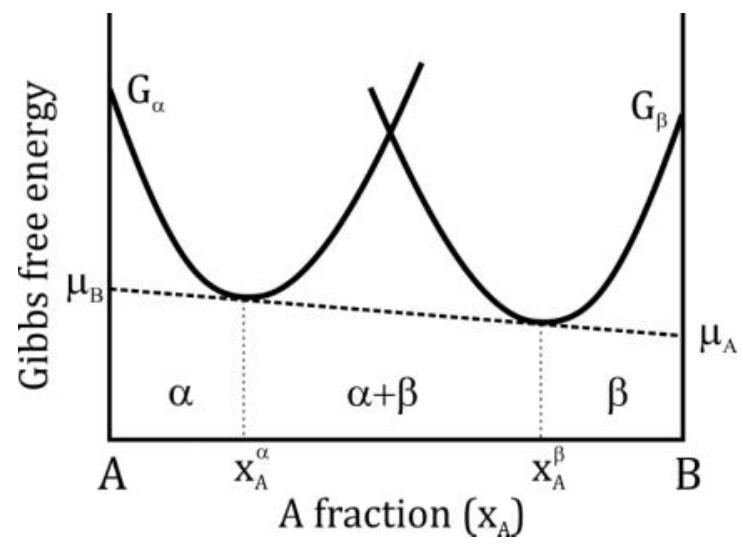

Figure 2.2: Equilibrium of $\alpha$ and $\beta$ phase shown by the tangent rule construction. Adapted from [28].

To predict the state to which a system wants to transform, it is important to know how the Gibbs free energy changes as a function of the parameter under consideration (e.g. composition, temperature). In alloys, different elements are mixed together and more than one phase can be stable for the same condition. Therefore, the Gibbs free energy becomes composition, temperature and pressure dependent.

A simplified example is where A and B atoms are mixed together but they do not have the same crystal structure in their pure state, one being $\alpha$ phase and the other $\beta$. In this case, each phase will have its own Gibbs free energy curve, $G_{\alpha}$ and $G_{\beta}$. The equilibrium between the two phases will be reached when the chemical potential of each component (A and $B$ ) is the same in each phase ( $\alpha$ and $\beta)$ :

$$
\mu_{A}^{\alpha}=\frac{\partial G_{\alpha}}{\partial X_{A}}=\frac{\partial G_{\beta}}{\partial X_{A}}=\mu_{A}^{\beta}
$$


This is equivalent to the common tangent rule, where the tangents to each $\mathrm{G}$ curve at the equilibrium composition lie on a common line as shown in Figure 2.2. For this example, the composition range with a high amount of $\mathrm{A}$ atoms will present the $\alpha$ phase, compositions rich in $\mathrm{B}$ atoms will show the $\beta$ phase, and a mix of both phases in between. The composition of $\alpha$ and $\beta$ phases cannot exceed the composition dictated by the common tangent, i.e. there is a miscibility gap.

The complexity increases when more elements $(\mathrm{A}, \mathrm{B}, \mathrm{C}, \ldots)$ and possible phases $(\alpha, \beta, \gamma, \ldots)$ are involved in a system. Nevertheless, the common tangent rule can always be applied and a similar condition for equilibrium is imposed to the system. The chemical potential of each element must be identical in every phase [28], i.e.

$$
\begin{aligned}
& \mu_{A}^{\alpha}=\mu_{A}^{\beta}=\mu_{A}^{\gamma}=\cdots \\
& \mu_{B}^{\alpha}=\mu_{B}^{\beta}=\mu_{B}^{\gamma}=\cdots \\
& \mu_{C}^{\alpha}=\mu_{C}^{\beta}=\mu_{C}^{\gamma}=\cdots
\end{aligned}
$$

For all examples above, the equilibrium state of an alloy was considered for a fixed temperature and pressure and only composition was varied. Once the temperature is taken into account, an equilibrium phase diagram can be constructed (see examples in Chapter 3).

In this thesis, phase transformations in $(\mathrm{Ti}, \mathrm{Al}) \mathrm{N}$ alloys were investigated by thermal activation at a fixed pressure, in a temperature range where the system is mainly in solid state. Therefore, most attention will be given to phase diagrams where composition and temperature are varied as shown in the following Chapter 3. 


\subsection{Diffusion}

In this thesis, phase transformation occurs via thermal activation, and diffusion is one fundamental mechanism involved. Diffusion is the movement of atoms, and it is induced by a gradient of the chemical potential. In general, there are two types of diffusion, downhill and uphill. In the first and most common, the atoms move to eliminate concentration gradients. In the second, the movement is towards the high concentration regions. These composition gradients are directly correlated to the chemical potential gradients of the components [28].

Furthermore, the capability of an atom to move in a system is defined as diffusivity. It depends on the type of element, the host phase and its surroundings (e.g. a surface). The differences depend on conditions such as the mechanism of diffusion (substitutional and interstitial), the probability of jumping to a vacant site, the number of vacancies, the chemical potential gradients and the temperature, among others. In an alloy, where differences in element diffusivity can exist, it is more complex to describe how atoms will move (diffuse).

One more important aspect to take in consideration for phase transformation is the presence of defects like grain boundaries, interfaces, dislocations, free surfaces, etc. In the vicinity of these defects, the diffusivity and the equilibrium conditions of a system may change, since they have a more open structure and the movement of atoms along them is much faster than in the lattice. These defects are also called high-diffusivity paths and under certain circumstances, they can be the dominant diffusion path and may control the phase transformation [28]. 


\subsection{Diffusional transformations in solids}

In the scope of this thesis, where the phase transformation path of $(\mathrm{Ti}, \mathrm{Al}) \mathrm{N}$ alloys was investigated at elevated temperatures, three diffusional transformations in solids are of relevance and discussed in more detail below.

\subsubsection{Nucleation and growth}

Nucleation is the self-organization of elements, structural and/or compositional, into a new phase. It occurs via formation of a small nucleus (embryo) inside a region of the system and it is the first step for phase transformation. It can be homogenous or heterogeneous. The first is the ideal case and it takes place randomly inside the system. The second is the most common and it occurs at suitable sites where the energy needed to form an embryo is lower than the homogenous case. Those places can be dislocations, grain boundaries, stacking faults, excess vacancies, inclusions, and free surfaces.

In order to form a stable embryo, there is an energy barrier $\left(\Delta \mathrm{G}^{*}\right)$ for nucleation to be overcome (Figure 2.3 (a)). This is related to three main contributions: volume generation, interface formation and a strain energy mismatch between the initial phase and the new phase. The first contribution minimizes the free energy of the system and is dominant above a critical embryo radius ( $\left.\mathrm{r}^{*}\right)$. The other two add additional energy to the system and are responsible for the nucleation barrier.

Once the nucleus of the new phase is stable, it will grow in order to decrease the Gibbs free energy of the system. This stage is called growth. A schematic view of how the composition varies with time in a nucleation and growth process is shown in Figure 2.3 (b). It starts with the nucleation of a phase with composition $\mathrm{X}_{2}$, in the matrix with composition $\mathrm{X}_{0}$, and it ends with two phases $\left(\mathrm{X}_{1}\right.$ and $\left.\mathrm{X}_{2}\right)$, where $\mathrm{X}_{1}$ is the composition of the depleted matrix. 
Sometimes the energy cost for nucleation is too high and intermediate phases are formed before reaching the equilibrium state. These phases may not have the lowest free energy but a low nucleation barrier, making them energetically favorable. This stepwise transformation occurs especially if there are differences in the crystal structure between initial and final state, e.g. formation of Guinier-Preston zones.

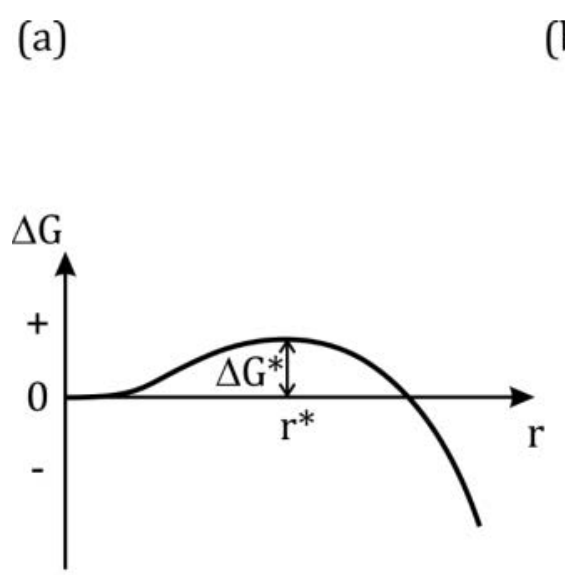

(b)
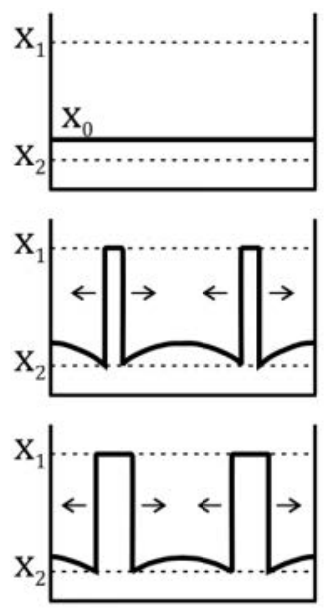

כี

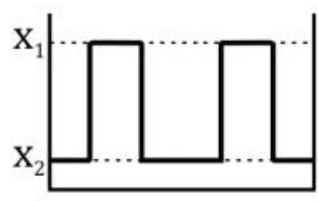

Distance

Figure 2.3: (a) Variation of Gibbs free energy with embryo radius $r$ for a homogenous nucleus, where $\Delta G^{*}$ is the nucleation activation barrier. (b) Schematic composition profiles at increasing time during nucleation and growth of precipitates with X2 composition. Modified from [28]. 


\subsubsection{Spinodal decomposition and coarsening}

Spinodal decomposition is a mechanism where an initial phase separates into two phases without a nucleation barrier (nucleation free). The condition for this to occur, is that the free energy of a given alloy must have a negative curvature, $\partial^{2} G / \partial X^{2}<0$, as shown schematically in Figure 2.4 (b) for the composition $\mathrm{X}_{0}$ at the temperature $\mathrm{T}_{2}$. Small fluctuations in composition will decrease the free energy of the system, and uphill diffusion will take place until equilibrium composition of both new phases, $\mathrm{X}_{1}$ and $\mathrm{X}_{2}$, is reached [29]. The only limitation is the diffusion which can be activated with temperature.

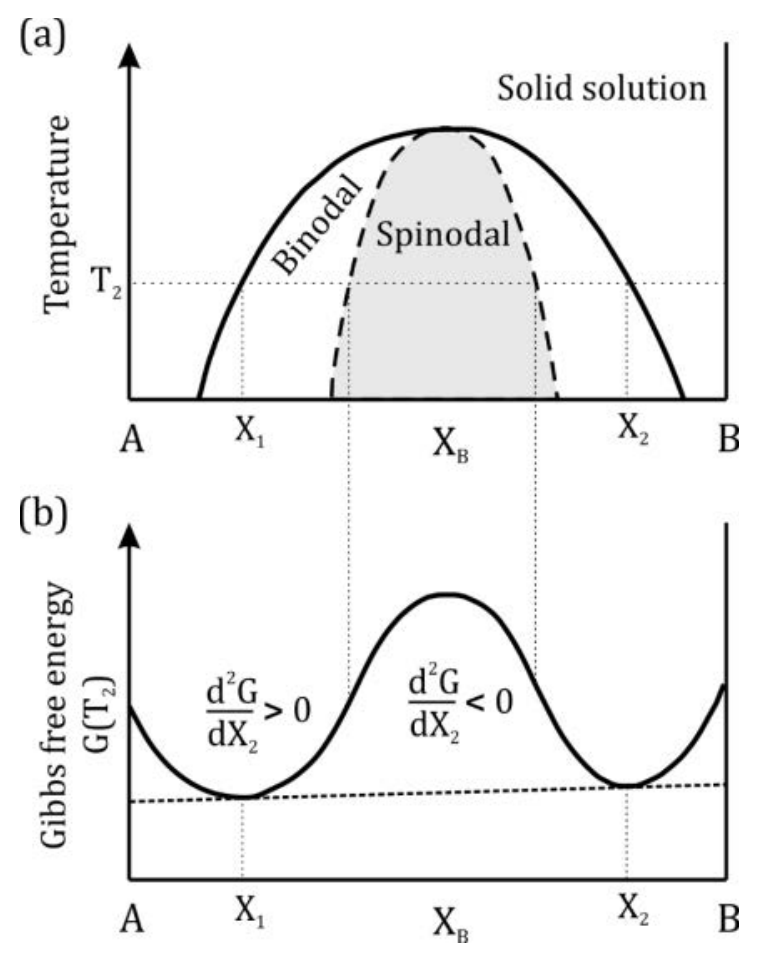

Figure 2.4: (a) Schematic phase diagram of a binary alloy presenting a miscibility gap and (b) the corresponding free energy curve at the temperature $T_{2}$. Modified from [28]. 
Spinodal decomposition possesses the following characteristics [30], as shown schematically in Figure 2.5:

- It occurs homogenously throughout the system (except near lattice defects) and it results in a finely disperse microstructure.

- The compositional fluctuations exhibit a certain wavelength during segregation, and the amplitude should increase continuously until a metastable state is reached.

- The interfaces between phases are diffuse.

(a)
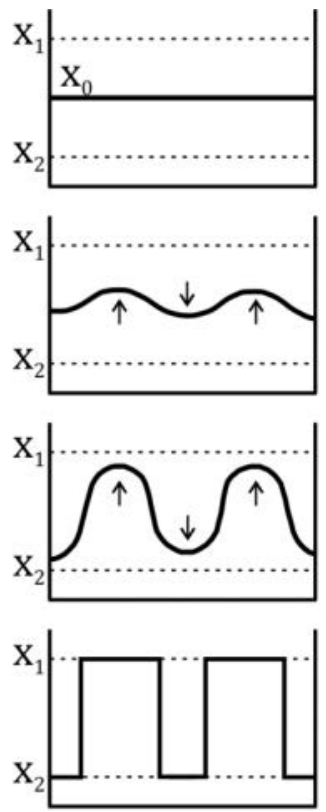

Distance (b)

\section{$\mathbf{0 s}$}
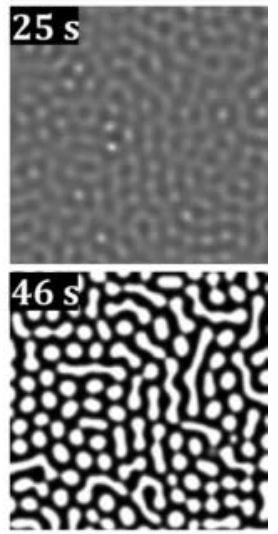

Figure 2.5: Schematic representation of an alloy during spinodal decomposition (into $X_{1}$ and $X_{2}$ ) as a function of time in a (a) $1 D$ composition profile [28] and (b) phase filed simulated $2 D$ microstructure [31], obtained by solving a modified Cahn-Hilliard equation.

This mechanism of transformation was first proposed by Hillert [29], and later improved and expanded to three dimensions by Cahn [30], [32] and Hilliard [33]. It occurs in 
systems that present a miscibility gap in their phase diagram, e.g. Au-Ni, which is usually defined by two regions: spinodal and binodal as shown schematically in Figure 2.4 (a). Nucleation-free decomposition occurs only inside the spinodal region, while in the binodal region, a phase separation through nucleation and growth takes place. The line dividing them is called spinodal and it is defined by a zero curvature of the Gibbs free energy $\partial^{2} G / \partial X^{2}=0$ (Figure 2.4). Cahn proposed that near the limit, yet still within the spinodal region, decomposition will be too slow so that the compositional fluctuations will reach a metastable state, and competing mechanisms like nucleation and growth will take over [30].

The kinetics describing the phase separation via spinodal decomposition are defined by the Cahn-Hilliard equation [33]:

$$
\frac{d c}{d t}=D \nabla^{2}\left(c^{3}-c-\gamma \nabla^{2} c\right)
$$

$\mathrm{D}$ is the diffusion coefficient, $\mathrm{c}$ is the concentration, and $\gamma$ is the surface energy. As the time advances, the concentration approaches a sinusoidal composition profile with a wavelength $(\lambda)$. The amplitude of the composition profile increases with time with a fixed $\lambda$ until a metastable equilibrium is reached as shown schematically for one dimension in Figure 2.5 (a).

An important parameter that determines the rate of spinodal decomposition is $\lambda$, i.e. the smaller $\lambda$ is, the faster the system decomposes. However, $\lambda$ cannot be predetermined for a system (alloy composition) since it depends on the initial intrinsic compositional fluctuations and on the principle of selective amplification (fluctuations with $\sqrt{2} \lambda_{\text {critical }}$ will grow faster and dominate) [30]. Only an upper limit in the spinodal decomposition rate can be set, the critical wavelength $\left(\lambda_{\text {critical }}\right)$, which depends on the interfacial energy and the coherency strain energy of the system. Therefore, below this $\lambda_{\text {critical }}$ decomposition cannot occur [28]. 
Once a wavelength dominates in the phase separation, this $\lambda$ will persist and the amplitude will increase until the system has reached the final composition of the phases, $\mathrm{X}_{1}$ and $\mathrm{X}_{2}$ (Figure 2.5 (a)) [28]. The following stage is called coarsening, where a growth of the domains with composition $\mathrm{X}_{1}$ and $\mathrm{X}_{2}$ will take place in order to minimize the interfacial and strain energy of the system [32]. During coarsening, there is no wavelength defining the evolution of the domain growth.

Only systems that present a miscibility gap in their phase diagram can be candidates for spinodal decomposition. The system studied in this thesis, metastable $(\mathrm{Ti}, \mathrm{Al}) \mathrm{N}$ with a B1 structure, is one of the systems presenting a miscibility gap which is shown and described in the following Chapter 3.

\subsubsection{Intercalation}

The ability to accommodate an elements or molecule by insertion between layers in a layered material is called intercalation [34]. There are different chemical and physical methods for activating this insertion and diverse inorganic hosts (graphite, clays, carbides, etc.) [34]-[37]. Only one is of interest in this thesis: the thermal activation of intercalation in transition metal nitrides/carbides for MAX phase formation. First, a brief introduction into MAX phases is given, followed by the description of the process of intercalation as a mechanism of phase transformation.

MAX phases $\left(\mathrm{M}_{n+1} \mathrm{AX}\right.$ phases, $\left.n=1,2,3\right)$ are a class of hexagonally structured nitrides and carbides that present a characteristic layered structure with $\mathrm{M}_{6} \mathrm{X}$ octahedral layers separated by A-element layers. $\mathrm{M}$ is an early transition metal (Ti, V, Cr, Zr, Nb, Mo, $\mathrm{Hf}, \mathrm{Ta}), \mathrm{A}$ is an A-group element (Al, Si, Ga, Ge, As, In, P), and X is carbon or nitrogen. The nomenclature depends on the amount of $M$ layers separated by A layers, e.g. $M_{2} \mathrm{AX}$ $(n=1), \mathrm{M}_{3} \mathrm{AX}_{2}(n=2)$ or $\mathrm{M}_{4} \mathrm{AX}_{3}(n=3)$ as shown in Figure 2.6 [38]. Their layered structure makes them a good candidate for intercalation. 
Intercalation in MAX phases was proposed for the first time by Zhou et al. [39], and presented later by Riley et al. as a low temperature solid state method for MAX phase synthesis without the formation of intermediate phases [40], [41]. In general, intercalation starts with a solid-state binary precursor $\left(\mathrm{M}_{1-\mathrm{n}} \mathrm{X}_{\mathrm{n}}\right)$ and an A-element source. Through thermal activation, a spontaneous rearrangement of the precursor into a layered structure makes the insertion of the A-element possible, and finally the formation of a MAX phase [40]. Intercalation is a reversible process [39], [42].

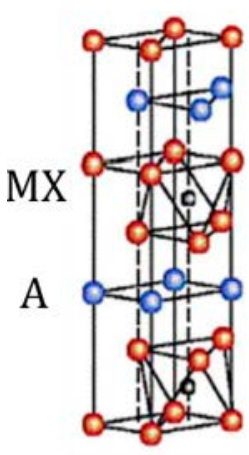

$\mathrm{M}_{2} \mathrm{AX}$

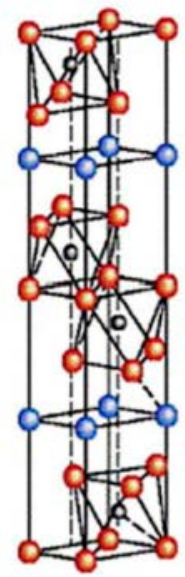

$\mathrm{M}_{3} \mathrm{AX}_{2}$

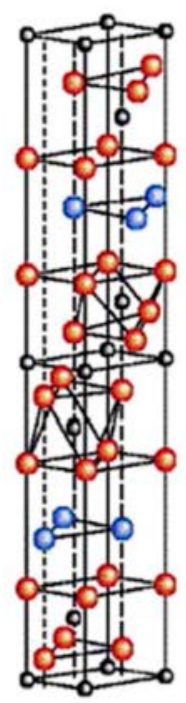

$\mathrm{M}_{4} \mathrm{AX}_{3}$

Figure 2.6: Crystal structures of the different MAX phase stacking sequences: $M_{2} A X, M_{3} A X_{2}$, and $M_{4} A X_{3}$ from Högberg et al. [43] adapted from Barsoum [44].

In order for intercalation to occur, a proper selection of the binary precursor must be done in which a rapid and highly selective diffusion can take place. The precursor must have crystallographic similarities with the MAX phase structure, and it must allow an unrestricted motion of constituent elements through sufficient diffusion "pathways" [41]. Examples for precursors are $\mathrm{MX}$ binaries with $\mathrm{NaCl}(\mathrm{B} 1)$ structure, like $\mathrm{TiC}_{\mathrm{x}}$ $(\mathrm{x}<1)$ and $\operatorname{TiN}_{\mathrm{x}}(\mathrm{x}<1)$, where the sub-stoichiometry in the non-metallic lattice 
enhances the X-element diffusivity [3]. The structures present similarities in the shared edges between $\mathrm{M}_{6} \mathrm{X}$ octahedral in MAX phases and the ones in the B1 structure [38], [45].

Once the precursor exists, the next step is the thermal activation in the presence of an A-element source, where a sequence of steps must occur spontaneously. These steps start with (a) the initial random distribution of X-element vacancies, (b) ordering of the vacancies, (c) twinning of the precursor sublattice, and finally (d) intercalation of A-element [41]. A schematic view of the transformation is shown in Figure 2.7.

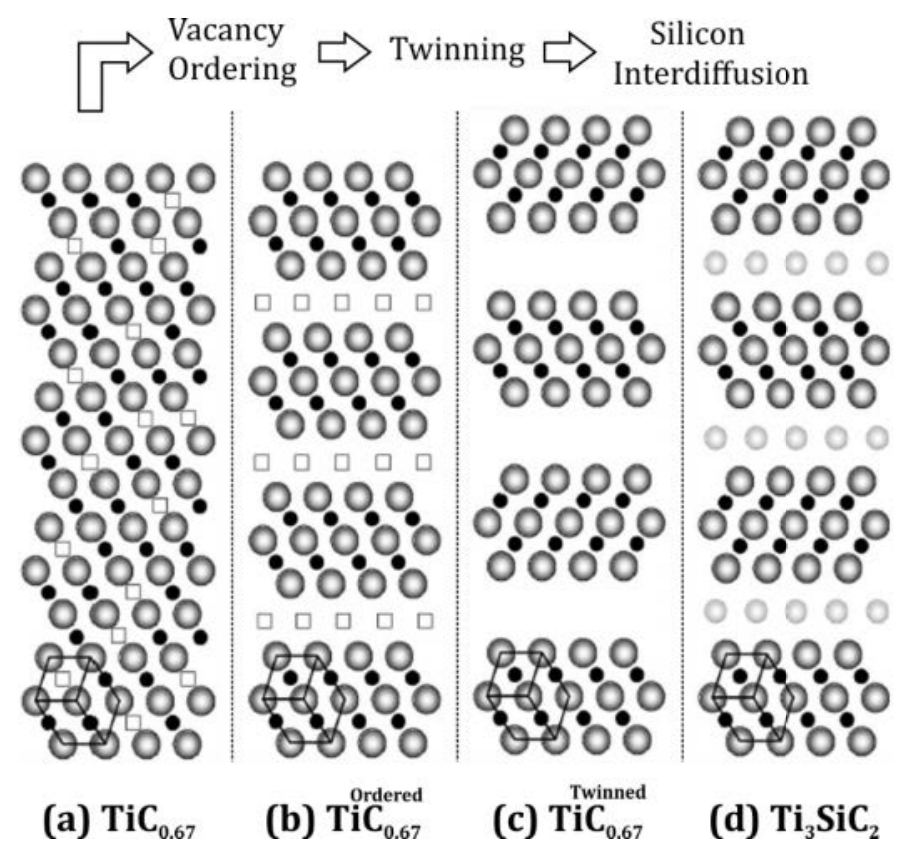

Figure 2.7: Proposed reaction mechanism of the intercalation of silicon into the customized solid state precursor, TiC0.67 by Riley et al. [41].

MAX phase formation via intercalation has been reported in different ternary systems, e.g. $\mathrm{Ti}_{3} \mathrm{SiC}_{2}, \mathrm{Ti}_{2} \mathrm{AlC}, \mathrm{Ti}_{3} \mathrm{AlC}_{2}$ [46]-[48]. Until now it has only been shown in ternary systems containing carbon as the $\mathrm{X}$-element. 
PHASE TRANSFORMATION 


\section{TI-AL-N SYSTEM}

The Ti-Al-N system has received considerable attention in the last three decades due to the technologically relevant materials obtained from this system either as bulk or as thin film. Various applications include TiN thin film diffusion barriers, AlN in electronic semiconductor devices, (Ti,Al)N wear-resistant coatings, high temperature composites like $\mathrm{Ti}_{2} \mathrm{AlN}, \mathrm{Al}_{3} \mathrm{Ti}, \mathrm{AlN}$, and TiN enhancing Al-base alloys, TiN embedded in steels preventing grain growth, etc [3], [6], [38], [49].

In order to obtain the desired material, it is important to understand and predict the phases formed in the system at different compositions, temperatures, pressures, etc. For that task, phase diagrams are of great help since they predict the thermodynamically stable phases for the different conditions. In the case of thin films, where it is possible to synthesize alloys far from thermodynamic equilibrium (like in the case of this thesis), additional data of the metastable phases is needed.

The prime material investigated in this thesis is the metastable cubic solid solution $\mathrm{B} 1-\left(\mathrm{Ti}_{1-\mathrm{x}} \mathrm{Al}_{\mathrm{x}}\right) \mathrm{N}_{\mathrm{y}}$ alloy with a rock salt structure deposited as thin film, in a very wide metal and non-metal compositional range $(0.28 \leq \mathrm{x} \leq 0.63$ and $0.40 \leq \mathrm{y} \leq 1.0)$. To understand the thermal stability and the phase transformation of this alloy at high temperatures (up to $1400{ }^{\circ} \mathrm{C}$ ) and ambient pressure, all available data was revised. Therefore, the chapter is divided in two parts. Firstly, the thermodynamic stable phases in the multicomponent Ti-Al-N system are examined in terms of composition and temperature variation at fixed pressure (1 atm). Secondly, the available thermodynamic data of the metastable cubic solid solution $\mathrm{B} 1-\left(\mathrm{Ti}_{1-\mathrm{x}} \mathrm{Al}_{\mathrm{x}}\right) \mathrm{N}_{\mathrm{y}}$ is presented. Additionally, as a guide for the reader, the most relevant phases in this work, stable and metastable, and their structure data are presented at the end of this chapter. 


\subsection{Stable phases in the Ti-Al-N system}

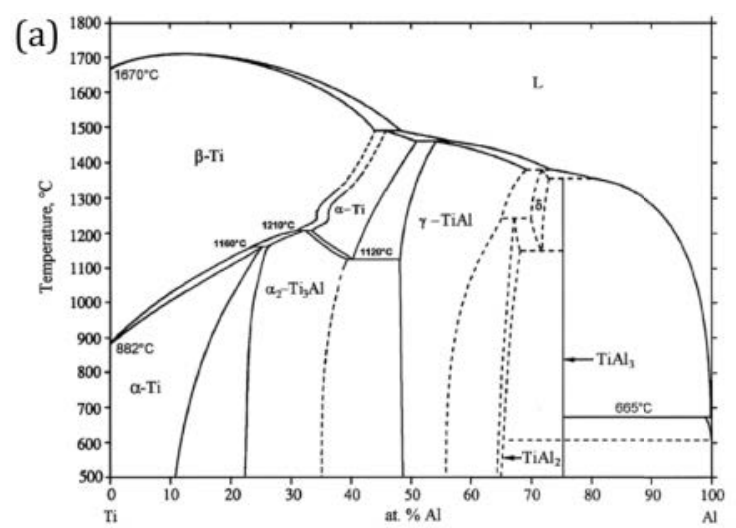

(b)

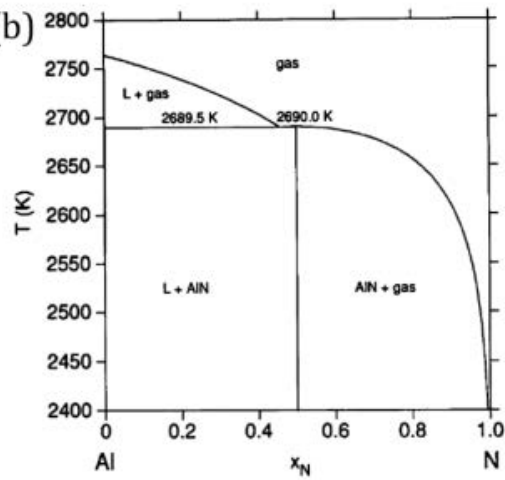

(c)

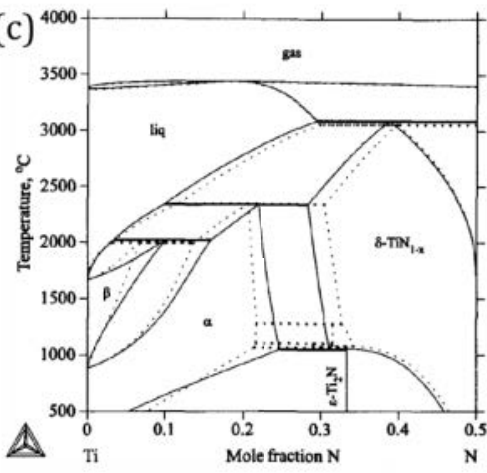

Figure 3.1: (a) Ti-Al phase diagram by Kainuma et al. [50], (b) Al-N phase diagram assessed by Hillert and Jonsson [51] and (c) Ti-N phase diagram assessed by Chen and Sundman [52].

The Ti-Al-N system presents a large variety of stable binary and ternary phases. The majority of the binary compounds are mixtures of $\mathrm{Ti}$ and $\mathrm{Al}$, and only three of them contain nitrogen. The Ti-Al mixtures are intermetallic phases: $\mathrm{Al}_{3} \mathrm{Ti}, \mathrm{AlTi}, \mathrm{AlTi}_{3}, \mathrm{Al}_{2} \mathrm{Ti}$ and $\mathrm{Al}_{5} \mathrm{Ti}_{2}$. Some have a wide compositional range of existence like $\mathrm{TiAl}$ and $\mathrm{AlTi}_{3}$, while others have a very narrow one like $\mathrm{Al}_{3} \mathrm{Ti}$ and $\mathrm{Al}_{2} \mathrm{Ti}$, as shown in Figure 3.1 (a). Their crystal structures are varied, e.g. $\gamma$-TiAl $\left(\mathrm{L}_{0}\right), \alpha_{2}-\mathrm{AlTi}_{3}\left(\mathrm{DO}_{19}\right), \mathrm{Al}_{3} \mathrm{Ti}\left(\mathrm{DO}_{22}\right)$. 
The three binary phases containing nitrogen are $\mathrm{AlN}$, TiN and $\mathrm{Ti}_{2} \mathrm{~N}$. AlN has a hexagonal (wurtzite) structure and a very narrow compositional range as shown in Figure 3.1 (b) [51]. This phase is a wide-band-gap (6.3 eV) semiconductor which does not accommodate any excess nitrogen or aluminum under thermodynamic equilibrium. $\mathrm{Ti}_{2} \mathrm{~N}$ presents a tetragonal structure with a narrow compositional range and it is stable only at low temperatures as shown in Figure 3.1 (c) [52]. Finally, TiN belongs to the transition metal nitrides (TMN) with a rock salt (B1) structure, which can be seen as two face-centered cubic $(f c c)$ structures with one unit cell shifted half an $a$-axis towards the other. One $f c c$ lattice is occupied by $\mathrm{Ti}$ atoms and the other by $\mathrm{N}$ atoms. One main characteristic of TMNs is that they can accommodate a large quantity of nitrogen deficiency via nitrogen vacancies in the $\mathrm{N}$ lattice [3], [53], making TiN stable over a large compositional range as it is shown in Figure 3.1 (c). TiN can also accommodate $\mathrm{N}$ overstoichiometry through metal vacancies [54].

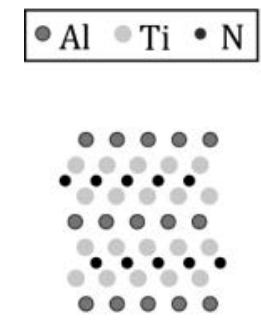

$\mathrm{Ti}_{2} \mathrm{AlN}$

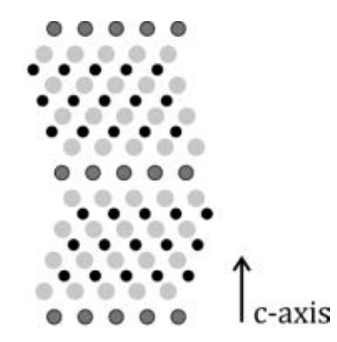

$\mathrm{Ti}_{4} \mathrm{AlN}_{3}$

Figure 3.2: Schematic stacking sequence along c-axis of MAX phases $\mathrm{Ti}_{2} A l N$ and $\mathrm{Ti}_{4} A l N_{3}$.

Only three ternary compounds are stable in the Ti-Al-N system: $\mathrm{Ti}_{2} \mathrm{AlN}, \mathrm{Ti}_{3} \mathrm{AlN}$ and $\mathrm{Ti}_{4} \mathrm{AlN}_{3}$. Ti $\mathrm{i}_{3} \mathrm{AlN}$ has a $\mathrm{L}_{2}$-type structure and can be obtained after prolonged annealing at relatively low temperatures, i.e. $1000{ }^{\circ} \mathrm{C}$ [52]. $\mathrm{Ti}_{2} \mathrm{AlN}$ and $\mathrm{Ti}_{4} \mathrm{AlN}_{3}$ belong to the MAX phases (for more details on MAX phases see Chapter 2 section Intercalation). Their structure is constituted by $\mathrm{Ti}_{6} \mathrm{~N}$ octahedral layers separated by $\mathrm{Al}$ layers, and depending on the amount $n$ of $\operatorname{Ti}_{6} \mathrm{~N}$ layers separated by A layers, it will be $\mathrm{Ti}_{2} \mathrm{AlN}$ ( $n=1$ layer) or $\mathrm{Ti}_{4} \mathrm{AlN}_{3}$ ( $n=3$ layers) [38]. The schematic view of their structure is shown in Figure 3.2. 
(a)
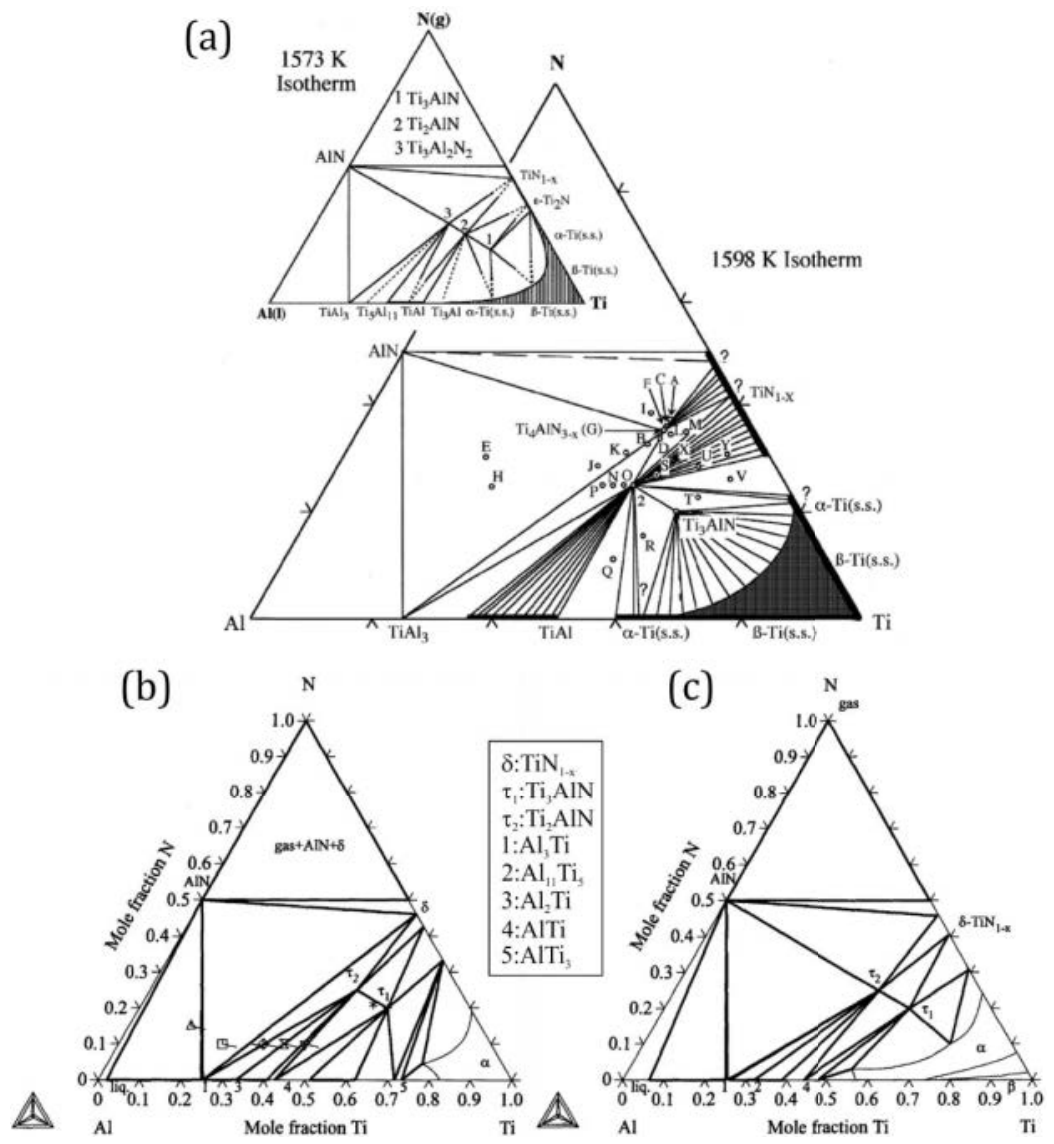

Figure 3.3: Isothermal sections of Ti-Al-N at (a) $1300^{\circ} \mathrm{C}$ assessed by Procopio et al. [55]. Insert on the left corner is the old phase diagram reported by Chen and Sundman [52]. (b) $900{ }^{\circ} \mathrm{C}$ and (c) $1200^{\circ} \mathrm{C}$ calculated by Chen and Sundman [52].

For the Ti-Al-N system both MAX phases have shown to accommodate $\mathrm{N}$ vacancies [56]-[58], making their compositional range broad. Among the ternary compounds $\mathrm{Ti}_{2} \mathrm{AlN}$ exists over a large temperature and composition range, i.e. 700 to $1600{ }^{\circ} \mathrm{C}$ (e.g. see Figure 3.3) [52]; while $\mathrm{Ti}_{4} \mathrm{AlN}_{3}$ has a very narrow temperature range around $1300{ }^{\circ} \mathrm{C}$, as shown by Procopio et al. in Figure 3.3(a) [55]. As side note, $\mathrm{Ti}_{4} \mathrm{AlN}_{3}$ was wrongly believed to be $\mathrm{Ti}_{3} \mathrm{Al}_{2} \mathrm{~N}_{2}$ until Barsoum et al. showed that it is the MAX phase $\mathrm{Ti}_{4} \mathrm{AlN}_{3}[59]$. 


\subsection{Metastable cubic solid solution $\left(\operatorname{Ti}_{1-\mathrm{x}} \mathrm{Al}_{\mathrm{x}}\right) \mathbf{N}_{\mathrm{y}}$}

Metastable solid solution $c-\left(\mathrm{Ti}_{1-\mathrm{x}} \mathrm{Al}_{\mathrm{x}}\right) \mathrm{N}_{\mathrm{y}}$ alloys with a $\mathrm{B} 1$ structure can be obtained as thin films in a wide compositional range with an aluminum metal fraction $\mathrm{x}<0.7$ [3] and a nitrogen to metal ratio $0.37 \leq \mathrm{y} \leq 1.02$ [54], [60], [61]. Their structure is similar to that of TiN, where two $f c c$ sublattices are interpenetrated. One $f c c$ lattice is randomly occupied by $\mathrm{Ti}$ and $\mathrm{Al}$ atoms, and the other by $\mathrm{N}$ atoms. Due to the technological relevance of this alloy as hard coating for cutting tools, extensive investigations on its thermal stability and phase transformations have being conducted. For the scope of this work, two relevant thermodynamic assessments are presented. The first is the quasi-binary TiN-AlN isostructural cubic phase diagram ( $\mathrm{N}$ stoichiometric case) which has been optimized lately by Shulumba et al. (Figure 3.4) [12]. The second is the phase decomposition pattern of the metastable cubic $\mathrm{Ti}_{1-\mathrm{x}} \mathrm{Al}_{\mathrm{x}} \mathrm{N}_{1-\mathrm{y}}$ in the presence of nitrogen vacancies ( $\mathrm{N}$ sub-stoichiometric case) calculated by Alling et al. via first principle calculations (Figure 3.5) [62].

The calculated phase diagram for $c-\left(\mathrm{Ti}_{1-\mathrm{x}} \mathrm{Al}_{\mathrm{x}}\right) \mathrm{N}$ shows a miscibility gap, and three regions can be distinguished: spinodal, binodal and the solid solution (Figure 3.4) [12], [63]. The first one corresponds to the spinodal region, where the metastable $c-\left(\mathrm{Ti}_{1-\mathrm{x}} \mathrm{Al} \mathrm{l}_{\mathrm{x}}\right) \mathrm{N}$ is subject to nucleation-free, isostructural phase separation into $c$-TiN and the metastable $c$-AlN (spinodal decomposition). In the binodal region, separation is also expected, but the phases $c$-TiN and $c$-AlN are formed via nucleation and growth. Finally, the solid solution region can be observed at high temperatures. The miscibility gap has an asymmetric shape with the maximum located at high $\mathrm{Al}$ content $(\mathrm{x} \approx 0.8)$ which is explained by the electronic structure mismatch between TiN and AlN, stronger in the Al-rich side [63]. Therefore, the driving force for segregation increases for alloys with high Al content. Furthermore, Shulumba et al. showed that lattice vibrations have a strong impact on the calculated $\mathrm{B} 1-\left(\mathrm{Ti}_{1-\mathrm{x}} \mathrm{Al} \mathrm{l}_{\mathrm{x}}\right) \mathrm{N}$ phase diagram by lowering the maximum of the miscibility gap from 6560 to $2860 \mathrm{~K}$ and increasing the solubility of AlN in TiN as shown in Figure 3.4 [12]. 


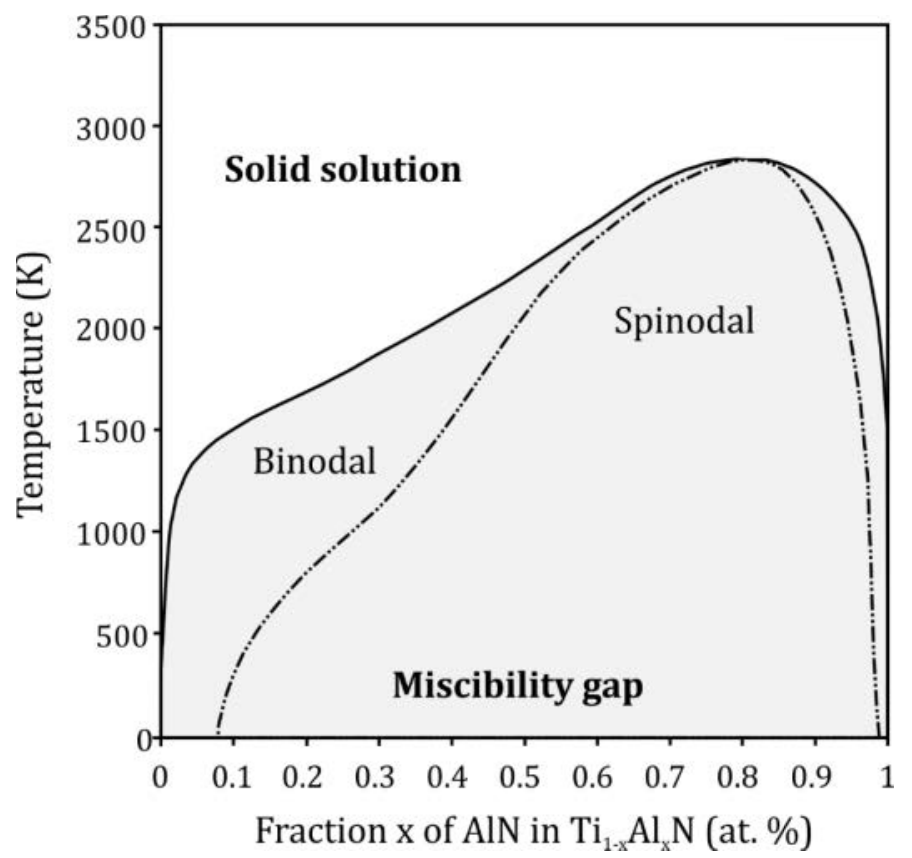

Figure 3.4: Calculated quasi-binary TiN-AlN phase diagram for B1-(Ti $\left.i_{-x} A l_{x}\right) N$ by Shulumba et al. [12]. Adapted figure showing only the miscibility gap calculated with the SIFC TDEP method where the anharmonic vibrational entropy contribution is included. The dash-dotted lines correspond to the spinodal metastable region and the solid line to the binodal. Abbreviations: SIFC = symmetry-imposed force constants; TDEP = temperature-dependent effective potential method.

Cubic AlN is a metastable phase with a B1 structure and a small volume mismatch with $c$-TiN in comparison to $w$-AlN with $c$-TiN, since a volume difference of $22.5 \%$ between $c$-AlN and $w$-AlN exists [64]. Under specific circumstances (e.g. solid solution $c$-(Ti,Al)N inside the miscibility gap), spinodal decomposition can take place. The formation of $c$-AlN is energetically favorable as an intermediate step during the phase transformation of $c$ - $(\mathrm{Ti}, \mathrm{Al}) \mathrm{N}$ into the stable phases $c$-TiN and $w$-AlN following the path:

$$
c-(\mathrm{Ti}, \mathrm{Al}) \mathrm{N} \rightarrow c-\mathrm{TiN}+c-\mathrm{AlN} \rightarrow c-\mathrm{TiN}+w-\mathrm{AlN}
$$

If enough energy is given to the system, $c$-AlN will eventually transform into the thermodynamic stable phase $w$-AlN via nucleation and growth [13], [63]. This 
transformation is not accounted for in the $\mathrm{B} 1-\left(\mathrm{Ti}_{1-\mathrm{x}} \mathrm{Al}_{\mathrm{x}}\right) \mathrm{N}$ phase diagram presented by Shulumba et al. (Figure 3.4), nor in the following decomposition pattern map, since only isostructural phase separation is considered and of relevance to predict.

The effect of nitrogen substoichiometry on the phase stability of the metastable cubic $\mathrm{B} 1\left(\mathrm{Ti}_{1-\mathrm{x}} \mathrm{Al}_{\mathrm{x}}\right) \mathrm{N}_{\mathrm{y}}(\mathrm{y}<1)$ alloys has been investigated by Alling et al. using static ab initio calculations [62]. They predicted the preferred isostructural decomposition pattern of $c-\left(\mathrm{Ti}_{1-\mathrm{x}} \mathrm{Al}_{\mathrm{x}}\right) \mathrm{N}_{\mathrm{y}}$ in the $\mathrm{x}-\mathrm{y}$ compositional space as shown in Figure 3.5. The length of the arrows represents the magnitude of the driving force for nucleation-free phase separation, and the arrows point toward the preferred decomposition direction. A point represents no driving force for nucleation-free phase separation. The map can be divided in three major regions according to Alling et al., which were schematically drawn in the map for a better visualization:

(1) High Al content, between N-rich and N-poor regions: Most energetically unstable compositional range. There are no reports of synthesis of stable or metastable cubic $(\mathrm{Ti}, \mathrm{Al}) \mathrm{N}$ alloys. Nevertheless, the use of epitaxial growth, pressure or a multilayer configurations could help obtain alloys in this range [65], [66].

(2) Close to $\mathrm{N}$ stoichiometry and medium-high Al content: Nitrogen tends to stick preferably to aluminum due to unfavorable accommodation of $\mathrm{N}$ vacancies in AlN which presents a semiconducting bonding [62]. On the other hand, TiN can accommodate the $\mathrm{N}$ vacancies due to its broad stable composition range in the $\mathrm{N}$ deficient side (see Figure 3.1 (c)), as has been shown experimentally [67].

(3) The N-poor, Ti-rich region: Strong driving force for precipitation of metallic Al or Al-Ti mixtures and tendency of $\mathrm{N}$ to stick to Ti. AlN formation is not energetically favorable since the phase does not accommodate $\mathrm{N}$ vacancies (see comment on region (2)), and all compositions between $\mathrm{Al}$ metallic mixtures and AlN are unfavorable. Alling et al. also mention that the formation of Ti-Al alloys 
or compounds has the same driving force as foret. stabilizing hexagonal MAX phases and cubic $\mathrm{Ti}_{3} \mathrm{AlN}$ perovskite [62].

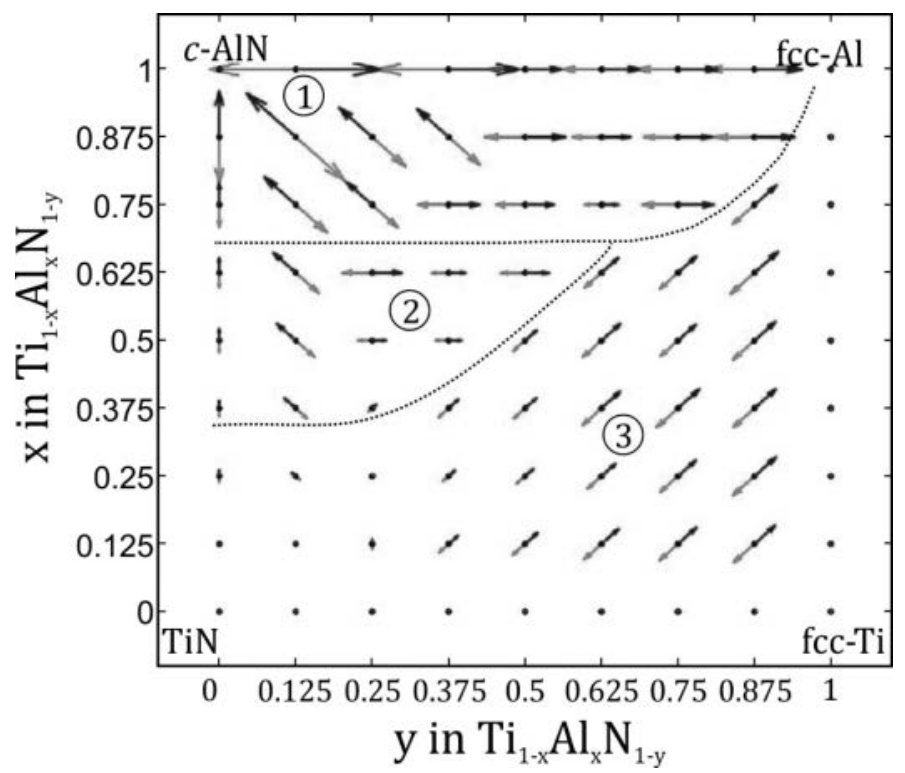

Figure 3.5: Energetically preferred decomposition pattern of $\left(T i_{1-x} A l_{x}\right) N_{y}$ in $x-y$ composition space calculated by Alling et al. [62]. The arrows point in the direction in which a phase separation would be most energetically favorable. Their length indicates the magnitude of this energy. Dot indicates no driving force for phase separation. Map modified from the original by adding a division of three regions. 


\subsection{Summary of relevant phases}

The information presented in this chapter should serves as a guide to predict and understand the phase evolution of metastable cubic solid solution $\left(\operatorname{Ti}_{1-\mathrm{x}} \mathrm{Al}_{\mathrm{x}}\right) \mathrm{N}_{\mathrm{y}}$ thin films, when the composition of the alloys is varied and the material is subjected to high temperatures. The relevant phases for this thesis and their respective structures are listed below:

\begin{tabular}{|c|c|c|c|c|}
\hline Phase & $\begin{array}{l}\text { Crystal } \\
\text { structure }\end{array}$ & ICDD \# & Space group & $\begin{array}{c}\text { Lattice } \\
\text { parameter }(\AA)\end{array}$ \\
\hline$(\mathrm{Ti}, \mathrm{Al}) \mathrm{N}^{*}$ & Cubic & Al-dependent & Fm3m (225) & $4.120<\mathrm{a}<4.241$ \\
\hline TiN & Cubic & $00-038-1420$ & Fm3m (225) & $\mathrm{a}=4.241$ \\
\hline AlN $^{*}$ & Cubic & 00-025-1495 & Fm3m (225) & $\mathrm{a}=4.120$ \\
\hline AlN & Hexagonal & $00-025-1133$ & P63mc (186) & $\begin{array}{l}a=3.111 \\
c=4.979\end{array}$ \\
\hline Ti2AlN & Hexagonal & $00-055-0434$ & $\begin{array}{c}\mathrm{P} 63 / \mathrm{mmc} \\
(194)\end{array}$ & $\begin{array}{c}a=2.989 \\
c=13.614\end{array}$ \\
\hline $\mathrm{Ti}_{4} \mathrm{AlN}_{3}$ & Hexagonal & $04-010-5108$ & $\begin{array}{c}\mathrm{P} 63 / \mathrm{mmc} \\
(194)\end{array}$ & $\begin{array}{c}a=2.988 \\
c=23.372\end{array}$ \\
\hline $\mathrm{Ti}_{6} \mathrm{Al}_{2} \mathbf{N}_{4}{ }^{*}$ & Hexagonal & This work & unknown & $\begin{array}{c}\mathrm{a}=2.988 \\
\mathrm{c}=56.2\end{array}$ \\
\hline $\mathrm{Al}_{3} \mathrm{Ti}$ & Tetragonal & 01-072-5006 & $\begin{array}{c}\mathrm{I} 4 / \mathrm{mmm} \\
\text { (139) }\end{array}$ & $\begin{array}{l}\mathrm{a}=3.853 \\
\mathrm{c}=8.583\end{array}$ \\
\hline $\mathrm{Al}_{5} \mathrm{Ti}_{2}$ & Tetragonal & 03-065-9788 & $\begin{array}{c}\mathrm{P} 4 / \mathrm{mmm} \\
(123)\end{array}$ & $\begin{array}{c}\mathrm{a}=3.905 \\
\mathrm{c}=7.4\end{array}$ \\
\hline
\end{tabular}

* Metastable phase. 
TI-AL-N SYSTEM 


\section{ThIn FILMS}

According to literature, a thin film is broadly considered as a layer of material with a thickness that can vary from an atomic monolayer up to several microns [3]-[5], [68]. It must show a difference of at least one order of magnitude between the lateral dimensions and the layer thickness, and it can be on a substrate (partially confined), confined between two materials or free-standing. Moreover, a multilayer is referred to as a stack of thin films. The process of synthesizing a thin film atom by atom from a source on a growth surface is called deposition, common methods of which are physical vapor deposition (PVD) and chemical vapor deposition (CVD) [4], [69]. The method and deposition parameters produce distinct microstructures and, consequently, properties. A deep understanding of this strong process-microstructure-properties correlation must thus be developed to achieve the desired properties, rendering the characterization of the thin film a crucial task.

In this thesis, a PVD process called cathodic arc evaporation was used for depositing (Ti,Al)N thin films, which is currently used for coating cutting tools [1], [2], [70]. The main focus lies on the characterization of the film microstructure and hardness in asdeposited and annealed (up to $1400{ }^{\circ} \mathrm{C}$ ) states. Therefore, the chapter is divided in two main sections: in the first one, the steps involved in the synthesis of a thin film by cathodic arc evaporation are described, as well as the employed experimental setup; the second part briefly introduces the characterization techniques used. Due to its relative novelty, atom probe tomography (APT) will be described in more detail as a nonstandard technique, as well as the different data analysis methods and graphical representations employed in this study. 


\subsection{Synthesis}

In general, the synthesis of a thin film by a PVD process requires three main steps; the first is the creation of a material vapor from a source, followed by the transport of the vapor phase to the substrate and, finally, the film growth through condensation of vapor species and nucleation. All three steps can be controlled independently to some extent, making PVD techniques versatile tools to control the microstructure and properties of the deposited films.

\subsubsection{Cathodic arc evaporation}

Cathodic arc evaporation belongs to the PVD processes where the vapor phase of the desired material source (cathode target) is obtained by heating it with a high current (30 - 400 A), low voltage (tens of volts) arc discharge that moves along the cathode surface either controlled or randomly [4], [69], [70]. The arc spot $\left(10^{-8}\right.$ to $10^{-4} \mathrm{~m}$ diameter) carries high current densities $\left(\sim 10^{8}\right.$ to $\left.10^{12} \mathrm{~A} / \mathrm{m}^{2}\right)$ which erode the cathode by melting and vaporization as well as particle ejection. The ionized plasma generated by the process consists of electrons, multivalent ions, neutral vapor atoms and droplets, where the desired species are the metal ions and neutrals. A schematic view of a cathodic arc evaporation system is shown in Figure 4.1. The arc is usually ignited by a mechanical striker and confined to the cathode surface by a boundary shield. The vapor with multivalent ions is responsible for sustaining the arc. While the arc spot movement is governed, to a certain extent, on cathode composition, gas species and pressure, presence of magnetic fields, etc. with a typical velocity of $\sim 100 \mathrm{~m} / \mathrm{s}$ [4]. Furthermore, the ions ejected from the cathode surface are typically accelerated towards the substrate by applying a negative bias voltage to the substrate, thus controlling the energy of the condensing species.

The relatively high possible ionization of the material atoms in the plasma (30 - $100 \%)$ [70], high kinetic energies $(10-200 \mathrm{eV})$ [71], and multiple charge states of the ions [70] 
are crucial parameters for the resulting microstructure and properties of the coating. These characteristics are responsible for relatively high deposition rates (e.g. $200 \mathrm{~nm} / \mathrm{min}$ ), a dense structure and good adhesion [2], [6], [70].

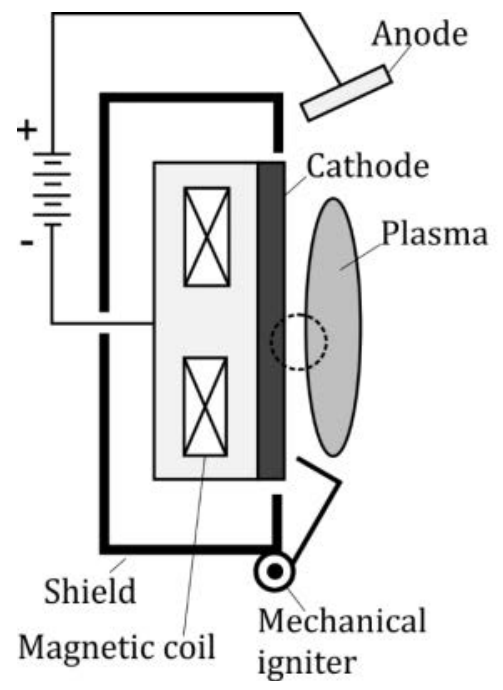

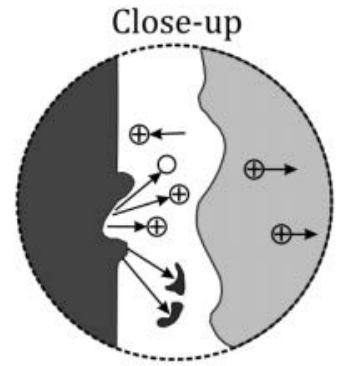

$\oplus$ Metal ion

O Neutral metal vapor AJ Microparticles

Figure 4.1: Schematic view of a cathodic arc deposition system with a model of the source emission. Adapted from Ohring [4].

Deposition of compound materials (nitrides, oxides, etc.) by cathodic arc evaporation is usually performed in a reactive atmosphere where some of the compound elements are evaporated from the cathode target, followed by their reaction with a gas (e.g. $\mathrm{N}_{2}, \mathrm{O}_{2}$ ) to form the desired compound. This variation of the technique is called reactive cathodic arc evaporation [69], [70]. It is preferably used for deposition of compound materials since evaporation of a compound target does not necessarily result in a vapor phase with the same composition, but rather a dissociation of the vapor species into fragments of the compound [69]. It is one of the most common deposition processes used for refractory nitrides, carbonitrides, and carbides in the cutting tool industry [1], [2], [4]. 
(a) Surface view

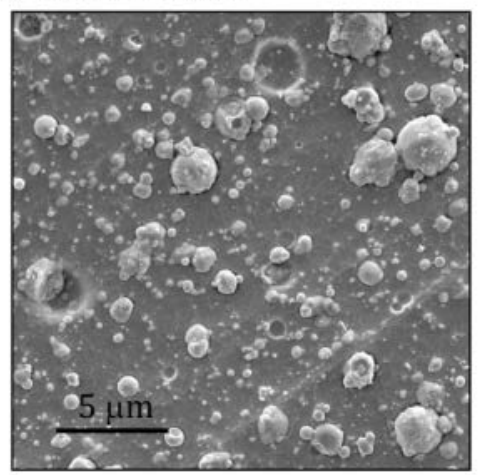

(b) Cross-section view

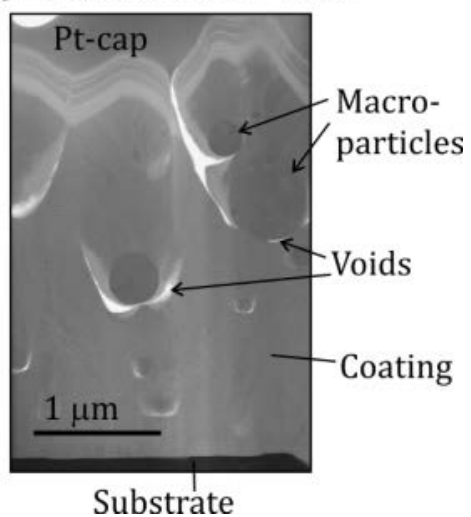

Figure 4.2: (a) SEM micrography of (Ti,Al)N film surface roughness due to macroparticles and (b) cross section in SE contrast of (Ti,Al)N thin film with embedded macroparticles.

One of the main disadvantages of this technique is the generation of macroparticles (droplets), which arise from the erosion of the cathode when the arc stays too long on one spot, locally melting the cathode [69]-[71]. The droplets arise from the ejection of liquid or solid particles due to thermal shock and hydrodynamic effects [4], resulting in a thin film with randomly embedded macroparticles. This leads to a disrupted film growth, an increase of the nucleation sites for new grains, a reduction in adhesion of the coating, an increase in surface roughness, and the creation of voids beneath and above them [2], [72], [73] as shown in Figure 4.2. Moreover, their composition tends to be more metallic compared to the reacted compound film (e.g. nitrides) [70], which can degrade the mechanical properties of the thin film. Size and density of the macroparticles can be controlled by the arc movement, deposition parameters or cathode target [69], [71], [74]. They can also be removed by the usage of a filter due to the differences in mass and properties, or by producing a diffuse arc [71], [75]. However, the deposition rate drops substantially and it becomes less attractive for industrial scale deposition. Therefore, no filter is used during industrial scale depositions, nor for the thin films deposited in this thesis. 
A second disadvantage of the cathodic arc evaporation process is the relatively high residual compressive stress caused by the high kinetic energy of the impinging ions, which generates lattice defects [3], [76], [77]. The compressive residual stresses are responsible for the increase in hardness since they also act as obstacles for dislocation movement and have a crack closing effect. Nevertheless, if the stresses are too high, delamination of the thin film can occur [3], [78].

\subsubsection{Film growth}

The final step involved in the synthesis of a thin film is its growth. This consists in consecutive nucleation, island growth, coalescence of islands, competitive grain growth, formation of a continuous structure, recrystallization and film thickness growth [79], [80]; making the evolution of the thin film structure a rather complex phenomenon. Therefore, a lot of effort has been put into understanding the correlation between deposition parameters and thin film microstructure, leading to the development and refinement of structure zone model (SZM) diagrams. SZMs should be a guideline to understand the mechanisms dominating the film growth, and thereby enable tuning of the deposition process parameters in order to obtain the desired microstructure and film properties.

There is no specific SZM for cathodic arc evaporated coatings, nevertheless a good approach is the model presented by Barna et al. for PVD thin films which is shown schematically in Figure 4.3 [79]. It was constructed by considering the role of impurities in addition to the most determinant atomic processes controlling the microstructure evolution: surface and bulk diffusion. Three main zones can be distinguished according to Barna et al.: Zone I, with low deposition temperatures, where porous and low density thins films are obtained with thin columns (1-10 nm) due to low surface and low bulk diffusion; Zone $T$, where surface diffusion is activated and a competitive columnar growth of the different crystal orientations takes place (here, texture changes with the film thickness); and Zone II, where surface and volume diffusion are active and high 
due to the high deposition temperatures, leading to wide columnar growth with similar orientation.

Cathodic arc evaporation films are typically located in the intermediate zone (zone T) since they present a dense columnar microstructure [2], [80]. A competitive columnar growth takes place at the beginning of the film growth and with increasing thickness, a dominant crystallographic orientation of the columns is observed [80].

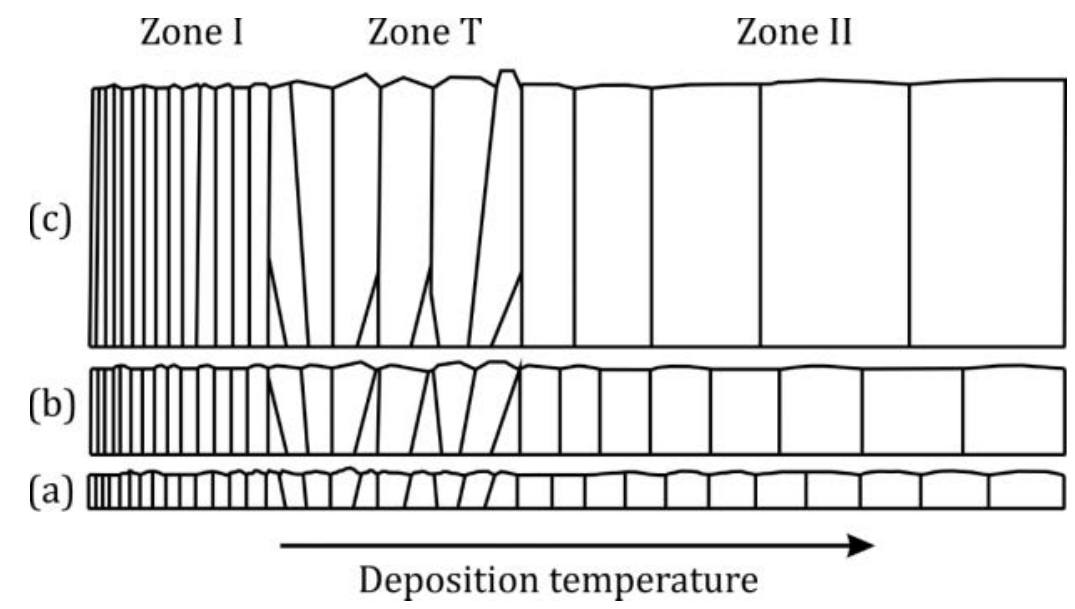

Figure 4.3: Structure zone model for PVD film growth for (a-c) different film thickness. Adapted from Barna et al. [79].

Surface and volume diffusion during film growth are primarily affected by the temperature. However, in the case of deposition of transition metal nitrides by PVD processes (cathodic arc evaporation), the synthesis temperature is low in comparison to the melting point of the material $\left(0.2-0.3 \mathrm{~T}_{\mathrm{m}}\right.$ of the material deposited) [3], [70] and the energetic particle bombardment can be used to modify the adatom mobilities and nucleation rates during deposition [80]. These factors lead to kinetic limitations during growth of thin films far from thermodynamic equilibrium conditions. Therefore, by using PVD processes, it is possible to have controlled synthesis of metastable phases or artificial structures [3], [80]. A good example, and the base of this thesis, is the deposition of metastable cubic solid solution $c$-(Ti,Al)N thin films with compositions 
inside the miscibility gap, where in thermodynamic equilibrium a demixing into $c$-TiN and $w$-AlN would be expected [52].

The appropriate selection of the deposition parameters (substrate negative bias, gas atmosphere, deposition pressure, substrate temperature, etc.) is crucial to achieve the desired microstructure and film properties.

\subsubsection{Experimental setup}

The deposition configuration used during this thesis consists of three circular cathodes of $100 \mathrm{~mm}$ in diameter mounted next to each other, facing a rotating cylinder where the substrates are placed, as shown schematically in Figure 4.4. During deposition, the cylinder is set to rotate, maintain a growth temperature of $\sim 450{ }^{\circ} \mathrm{C}$ and a deposition rate $0.1 \mu \mathrm{m} / \mathrm{min}$, while the total gas pressure is kept at $2 \mathrm{~Pa}$. A negative bias of - $30 \mathrm{~V}$ is used in all depositions unless stated otherwise. In order to study the effect of aluminum metal fraction when changing a deposition parameter, cathodes with different metal ratios (Ti:Al) were selected: 33:67, 45:55 and 100:0. Two different substrates were used: Fe foil and cemented carbide (ISO SNUN120408) comprising tungsten carbide (WC) with a 12 wt. \% Co binder and less than 2 wt.\% of other carbides, e.g. tantalum carbide. The first substrate was used for obtaining free-standing thin film since the Fe foils can be dissolved in $\mathrm{HCl}$. The second one was selected so as to measure hardness and determine film-substrate interaction.

Three main deposition conditions were used in this thesis:

1. A mixed reactive gas atmosphere. Ar and $\mathrm{N}_{2}$ gas were mixed in different ratios at a fixed total gas pressure, in order to reduce the nitrogen content of the deposited thin films.

2. An increase in negative bias voltage on the substrate. The kinetic energy of the ions arriving at the substrate was varied by changing the bias voltage in order to change the microstructure of the thin film. 
3. A multilayer configuration. Deposition of (Ti,Al)N/TiN multilayers was implemented in order to have a predefined artificial structure and observe the effect of increasing interfaces.

For the (Ti,Al)N multilayer deposition, pure Ti cathodes were placed on the opposite side of the rotating cylinder (sample holder) in relation to the Ti:Al cathodes (Figure 4.4). This way, a multilayer configuration was obtained. The bilayer thickness was varied with the speed of the cylinder.

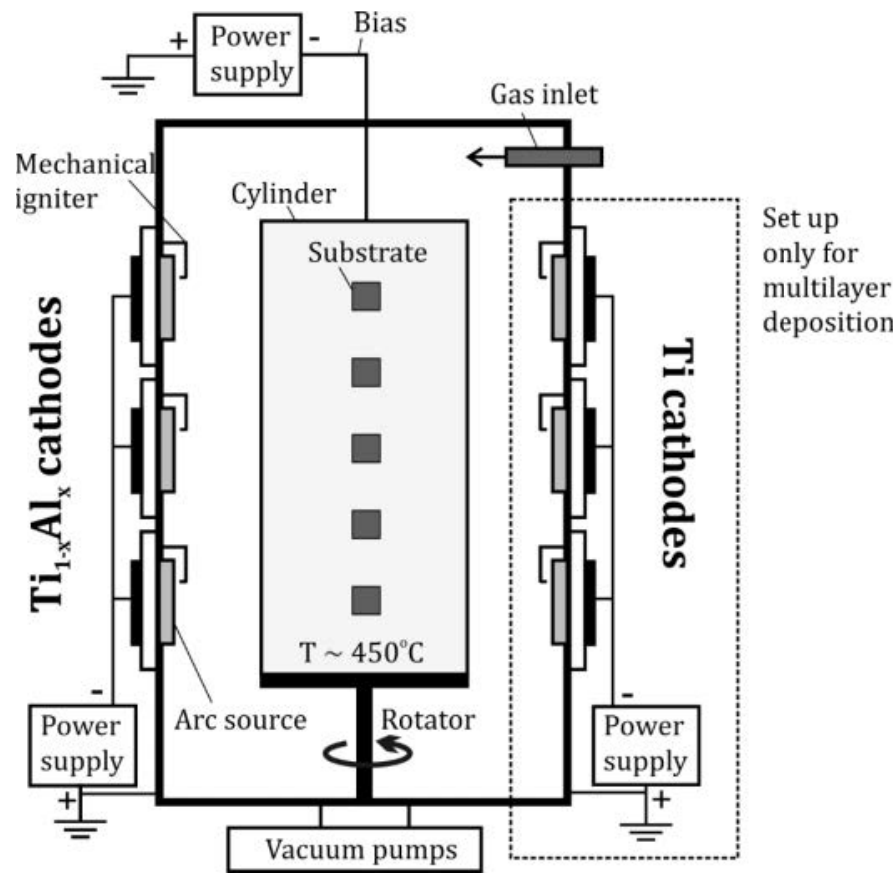

Figure 4.4: Schematic view of the deposition setup used for the synthesis of the thin films investigated in this thesis. 


\subsection{Characterization techniques}

The characterization of thin films is not a trivial task. Challenges arise from the combination of the material and the limited dimensions of the film with the limitations and pre-requirements of the characterization technique. More specifically: the thickness of the thin film, the amount of material available for analysis, the change in microstructure along film thickness, the substrate used, the difficulty of quantitative chemical analysis (especially light elements) and structural analysis, the sample preparation and other challenges must be overcome for unambiguous characterization of the thin film microstructure and properties [81]. Therefore, it is of great relevance to choose the appropriate characterization techniques and to combine different techniques that cover different scales and information about the thin film.

The techniques used during this study are presented below with a description of the setup and parameters used. The main focus was on microstructure and hardness characterization of as-deposited and annealed thin films.

\subsubsection{Differential scanning calorimetry}

The thermal response of $(\mathrm{Ti}, \mathrm{Al}) \mathrm{N}_{\mathrm{y}}$ alloys and (Ti,Al)N/TiN multilayers was measured in a differential scanning calorimeter (DSC) Netsch STA 449C operating with an argon flow of $50 \mathrm{ml} / \mathrm{min}$. An alumina crucible holding $50 \mathrm{mg}$ of the sample in powder form was used for each measurement. A zirconium oxygen getter was placed in the vicinity of the sample to avoid oxidation of the samples. First, samples were outgassed at $250{ }^{\circ} \mathrm{C}$ for one hour, directly followed by heating to $1400{ }^{\circ} \mathrm{C}$ with a rate of $20^{\circ} \mathrm{C} / \mathrm{min}$. A second run was used as baseline and subtracted from the first measurement [82]. In some cases, a thermogravimetry (TG) measurement was coupled in order to obtain information about mass change attributed to phase transformations. Following the convention in the hard coating field, exothermic reactions are plotted upwards. 
In addition, the DSC was used to heat powder samples to intermediate temperatures under the same conditions as stated above, to track the phase transformation sequence. A single heating cycle up to the desired temperature and $15 \mathrm{mg}$ of powder were used. The maximum temperatures ranged from 700 to $1400{ }^{\circ} \mathrm{C}$ in $100{ }^{\circ} \mathrm{C}$ or $50{ }^{\circ} \mathrm{C}$ steps, when necessary.

Powder samples were obtained by deposition of the thin film material on Fe foils followed by a removal of the latter. First, the Fe foil was thinned mechanically by backside grinding, and then dissolved in hydrochloric acid (37\%). A magnet was used to confirm complete dissolution of the substrate. The recovered coating flakes were cleaned with distilled water and acetone and ground into a fine powder. The particles presented a flake-like shape approximately 30 - $80 \mu \mathrm{m}$ long, fulfilling the criteria of a free-standing thin film. This Fe foil removal process has proven to yield a powder with the same stoichiometry and crystal structure as the deposited coating [83]. It also achieves a complete dissolution of the macroparticles generated during cathodic arc deposition, since the composition is of a more metallic nature.

\subsubsection{X-ray diffraction}

Phase analysis, preferred orientation (texture) and stress measurements were carried out in a PANalytical X'Pert PRO MPD and a PANalytical Empyrean diffractometer using $\mathrm{Cu} \mathrm{K} \mathrm{K}_{\alpha}$ radiation. A focusing, symmetric Bragg Brentano configuration was used for phase analysis. In this setup, only lattice planes parallel to the sample surface contribute to the diffraction peaks. Additional low-background optics were used in the PANalytical Empyrean diffractrometer. The diffractograms were recorded at room temperature either as-deposited or after annealing. A silicon zero diffraction plate was used as sample holder in order to reduce background signal. Stress measurements were performed on the 422 diffraction peak of $c$ - $(\mathrm{Ti}, \mathrm{Al}) \mathrm{N}$ by using the $\sin ^{2} \psi$ method. The elastic constants used to convert the strain measurements to stress are: $E=460 \mathrm{GPa}$ and $v=0.20$, obtained from $a b$ initio calculations [18]. Pole figure measurements were 
performed in the main reflections 111, 200 and 220 of the $c-(\mathrm{Ti}, \mathrm{Al}) \mathrm{N}$ structure with a resolution of three degrees for $\psi$ and $\varphi$.

Phase analysis was performed in all as-deposited and annealed powder samples and coatings on cemented WC/Co-based substrates. Due to the predominant flake-like particle shape of the powder samples, preferred crystallographic orientation was measured in as deposited $c$ - $(\mathrm{Al}, \mathrm{Ti}) \mathrm{N}_{\mathrm{y}}$ powder samples. This way, the effect of a reminiscent preferred orientation could be separated from the change in structure factor caused by the $\mathrm{N}$ vacancies accommodated in the $\mathrm{B} 1$ crystal structure. Stress measurements were performed only in the as-deposited $c-(\mathrm{Ti}, \mathrm{Al}) \mathrm{N}_{\mathrm{y}}$ coatings on WC/Co substrates where the applied substrate bias was varied, since a change in the residual compressive stresses was expected.

\subsubsection{Transmission electron microscopy}

Transmission electron microscopy (TEM), scanning TEM (STEM) and selected area diffraction (SAD) were used to characterize the microstructure and crystal structure of some samples in more detail. For samples in paper I to III, TEM imaging and selected area diffraction were performed in a JEOL JEM 2010 at an acceleration voltage of $200 \mathrm{kV}$. TEM/STEM analysis was carried out using a cold field emission gun JEOL JEM-ARM 200F at $200 \mathrm{kV}$ equipped with a STEM Cs corrector (CESCOR, CEOS $\mathrm{GmbH})$. A high angle annular dark-field (HAADF) detector was used for Z-contrast STEM imaging (paper II). Some of the FIB-prepared TEM thin lamellae received an additional thinning with an Ar Ion gun (Nanomill Mod. 1040, Fischione) for high-resolution imaging (paper II). The Ar ion beam current used was $125 \mathrm{pA}$ for $20 \mathrm{~min}$ at a tilt angle of $\pm 10^{\circ}$.

For paper IV and V, cross sectional TEM samples were prepared through mechanical grinding and polishing, followed by Ar ion beam milling in a Gatan 691 precision ion polishing system until the sample was electron transparent $(<100 \mathrm{~nm})$. These samples were investigated in an energy-filtered analytical transmission electron microscope 
(EFTEM) using a cold field emission gun JEOL JEM-ARM 200 operated at an acceleration voltage of $200 \mathrm{kV}$. STEM imaging was performed in a FEI Tecnai G2 TF 20 UT microscope at an acceleration voltage of $200 \mathrm{kV}$ using a high angle annular dark field detector.

\subsubsection{Scanning electron microscopy}

A scanning electron/focused ion beam (SEM/FIB) microscope, FEI Helios NanoLab600, was used for surface morphology imaging, cross section preparation, scanning transmission imaging (in SEM), energy dispersive X-ray analysis (EDS), and electron backscatter diffraction (EBSD). In situ lift-out techniques were used to prepare samples for transmission electron microscopy [84] and atom probe tomography (APT) [85] with a final cleaning step of $2 \mathrm{kV}$ FIB milling. More details on APT sample preparation will be given in the respective section of this chapter.

Investigations of the chemical and phase distribution were performed by EDS and EBSD in some samples in paper III complementary to APT, due to the relatively large size of the inhomogeneities across the film thickness.

\subsubsection{Nanoindentation}

Hardness measurements of $(\mathrm{Ti}, \mathrm{Al}) \mathrm{N}_{\mathrm{y}}$ thin films on WC/Co-based substrates were performed with an UMIS nanoindentor using a Berkovich diamond tip. To avoid effects of surface topography on hardness measurements, the samples were prepared as tapered cross sections (taper angle $\sim 10^{\circ}$ relative to the sample surface) by mechanically grinding and polishing to a mirror-like finish using a $1 \mu \mathrm{m}$ diamond suspension in the final step. A maximum load of $50 \mathrm{mN}$ and 30 to 50 indents for each sample were used with fused silica as reference. The indentation depths for this amount of load were around $250 \mathrm{~nm}$, which is less than $10 \%$ of the film's thickness. Average hardness values were obtained using the Oliver and Pharr method [86]. 
The hardness behavior at high temperatures was obtained from post-annealing hardness measurements of coatings on WC/Co-based substrates (paper III and IV). The annealing was performed in a tube furnace at a vacuum of $7 \times 10^{-4} \mathrm{~Pa}$. Isothermal annealing treatments were performed at $\mathrm{T}_{\max }=700,800,900,1000,1100$, and $1200{ }^{\circ} \mathrm{C}$ for $15 \mathrm{~min}$ with heating and cooling rates of $20^{\circ} \mathrm{C} / \mathrm{min}$.

\subsubsection{Elastic recoil detection analysis}

Elemental composition of some as-deposited (Ti,Al) $\mathrm{N}_{\mathrm{y}}$ samples on WC/Co based substrates was measured by Time-of-Flight Energy (ToF-E) Elastic Recoil Detection Analysis (ERDA). The measurements were performed using a $36 \mathrm{MeV}{ }^{127} \mathrm{I}^{8+}$ ion beam with an incident angle of $67.5^{\circ}$ relative to the surface normal and a spot size of $2 \mathrm{~mm} \times 2 \mathrm{~mm}$. Forward scattered recoil ions were detected with a time-of-flight energy detector at an angle of $45^{\circ}$ with respect to the incoming ion beam [87]. The measured recoil ToF-E spectra were converted off-line into relative atomic concentration profiles using the CONTES code [88].

The technique requires a surface roughness in the nanometer range and inhomogeneities smaller than the ion beam spot cannot be detected. This is why the technique does not yield reliable results of samples containing high amounts of macroparticles, i.e. $c$ - $(\mathrm{Ti}, \mathrm{Al}) \mathrm{N}_{\mathrm{y}}(\mathrm{y}<0.9)$. However, it was mainly use to cross-validate compositional measurements of the cubic solid solution phase with atom probe tomography for samples with low amount of macroparticles (paper I), i.e. $c$ - $(\mathrm{Ti}, \mathrm{Al}) \mathrm{N}_{\mathrm{y}}(\mathrm{y}>0.9)$. 


\subsection{Atom Probe Tomography}

Atom probe tomography (APT) is a powerful destructive technique that gives chemical and spatial information with near-atomic resolution (at least $0.04 \mathrm{~nm}$ in depth and $0.20 \mathrm{~nm}$ laterally) [89], [90]. It combines a 3D visualization of atomic-scale microstructure with quantitative data analysis. One of the strengths of APT is the ability to measure all the elements (light to heavy) with an equivalent efficiency. A wide range of materials including metals, semiconductors, ceramics and limited biological or organic materials [91]-[93] can be measured [94]-[96]. The volume investigated is usually small (approx. $100 \mathrm{~nm}$ x $100 \mathrm{~nm}$ x $200 \mathrm{~nm}$ ) meaning that the scientific questions to be solved with atom probe must be in the nanometer scale.

\subsubsection{Principle of operation}

The main principle is the controlled field evaporation $(\sim 10-50 \mathrm{~V} / \mathrm{nm})$ atom by atom from a very sharp tip ( $50 \mathrm{~nm}$ radius $)$ in ultra-high vacuum $\left(\sim 10^{-11} \mathrm{mbar}\right)$ at cryogenic temperatures $(>15 \mathrm{~K})$. Atoms at the surface of the tip are ionized and field evaporated with the combined effect of a laser or voltage pulse applied to the specimen and a static electric field that accelerates the ions toward a 2D detector. The experimental setup for atom probe tomography is shown in Figure 4.5.

The evaporation field $(F)$ required for ionization depends on the elements, phases and their atomic bonding (crystal structure and bond type) and typically ranges from 10 to $50 \mathrm{~V} / \mathrm{nm}$. The field at the apex of an APT sample is calculated as follows [96]:

$$
F=\frac{V}{k_{f} R}
$$

where $V$ is the applied high voltage, $R$ the tip radius and $k_{f}$ is a field factor that takes into account the tip shape and its electrostatic environment [97]. The evaporation field during the measurement can be estimated from the ratio of different charge states of an 
ion by using the Kingham curves [98]. This can be combined with SEM images before and after run of the APT tip, in order to obtain tip shape information.

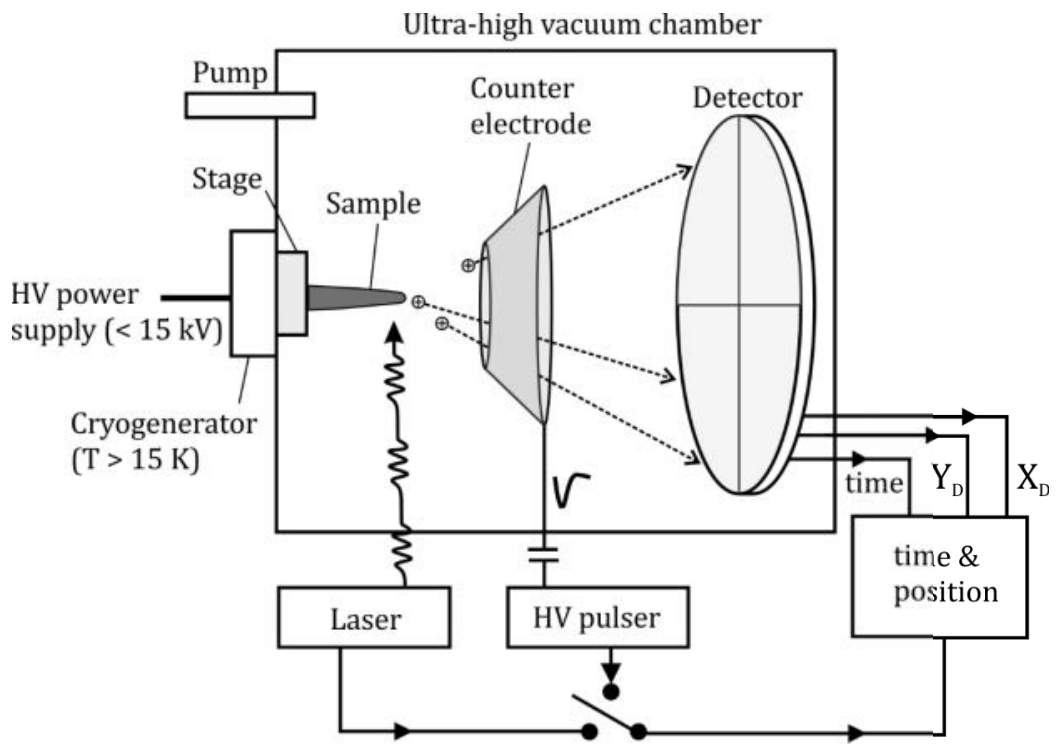

Figure 4.5: Experimental setup for local electrode atom probe tomography with a $2 D$ detector, after [96].

Once the ions are field evaporated, they are accelerated towards a microchannel plate in front of the detector where the signal is amplified by converting a single ion into a cloud of electrons. These reach a delay-line detector and the positions in $x$ and $y$ are recorded. Since the ions are field evaporated by a controlled pulse and accelerated by a known electrostatic field, the time of flight $\left(t_{f l i g h t}\right)$ of the ion can be used to determine its mass-to-charge ratio $(\mathrm{m} / \mathrm{q})$ :

$$
\frac{1}{2} m v^{2}=q V \quad ; \quad v=\frac{L}{t_{\text {flight }}} \stackrel{\text { lead to }}{=} \quad \frac{m}{q}=2 V\left(\frac{t_{\text {flight }}}{L}\right)^{2}
$$

where $v$ is the velocity, $m$ is the mass and $q$ is the charge of the ion, $V$ is the total voltage and $L$ the flight length. 
The collected time-of-flight information (independent of the ion position) during an APT measurement is generally represented as a histogram called mass-to-charge spectrum or mass spectrum (Figure 4.6). The units of $m / q$ are commonly expressed in Daltons ( $\mathrm{Da})$. The elemental nature of the ions can be identified by measuring the mass-to-charge-state ratio, since every element has a characteristic number of isotopes with a fixed natural abundancy.

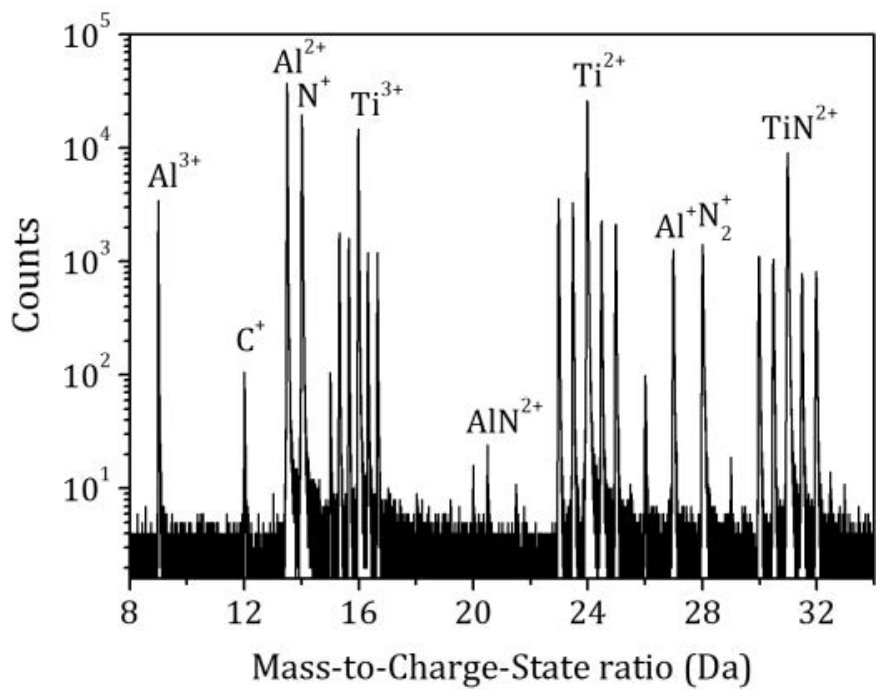

Figure 4.6: Mass-to-charge spectrum of a $(T i, A l) N$ sample.

The 3D reconstruction requires post-processing of the acquired data with specialized software based on an algorithm (protocol) that calculates the original position of the detected ions by a reverse-projection onto the surface of a virtual specimen. The basic protocol used in most software was published by Bas et al. [99]. It assumes that the tip is a truncated cone with a hemispherical cap, that the ions are projected along a straight trajectory (point-projection) and that the atoms are field evaporated layer-by-layer from the outermost shell inwards. That way, the $z$ position of the ions can be calculated from the sequence of detection, and in combination with the detected $x, y$ coordinates and the time-of-flight, a 3D reconstruction with chemical information can be made. Four fundamental parameters are required for a reconstruction: the evaporation field, the field 
factor (tip geometry and electrostatic field dependency), the image compression factor (tip shape dependent) and the detection efficiency of the instrument.

The reconstruction of the APT tip is the first approach of a visual analysis of the data and depending on the type of information to be extracted, different algorithms and analysis tools are implemented. The tools used in this thesis are presented at the end of this chapter.

\subsubsection{Limitations in APT}

As any technique, APT has its limitations and it is important to have them in mind when performing data analysis and visualization. Artifacts in a reconstruction can arise due to the nature of the material such as presence of phases with different evaporation fields, grain boundaries, interfaces, clusters/segregations, bad thermal transport at cryogenic temperatures, etc. [96]. Also, a bad choice of measurement parameters, the specimen tip shape (no perfect hemisphere and shank angle) or a wrong choice of reconstruction parameters can lead to misleading results. Some of the main limitations encountered in this thesis and how they were mitigated are listed below.

\section{$\underline{\text { Thermal tails in mass-to-charge peaks }}$}

They appear in laser mode when the heat from the laser pulse is not carried away fast enough. A longer cooling time of the tip can cause ions to be emitted shortly after the pulse (peak tail) and between pulses (background). Thermal tails can affect the accuracy of composition measurements since peaks may overlap or be completely hidden in the tail of another peak [96]. Tip shape (large shank angles) and measurement parameters (laser power and repetition rate, specimen temperature) can help to mitigate the effect. 


\section{$\underline{\text { Complex ion evaporation }}$}

The evaporation of complex ions (e.g. $\mathrm{TiN}^{+}, \mathrm{CN}^{+}, \mathrm{N}_{2}{ }^{+}, \mathrm{Ti}_{2} \mathrm{~N}^{+}$) in compound materials containing nitrides, carbides and oxides is commonly observed (e.g. Figure 4.6). This process reduces the depth resolution of the atom probe [100]. It also leads to additional peaks in the mass spectrum, making unambiguous assignment more complicated and potentially causing peak overlap. Reduction in the laser power (in laser mode) decreases the amount of complex ions when measuring nitrides [101].

\section{Multiple event detection}

It is a common limitation in the delay-line position-sensitive detectors. It takes place when multiple events (i.e. ions) arrive close in time or/and in location. The extension of the signal loss is difficult to quantify since the exact number of ions emitted is unknown and some get lost in the detection efficiency of the detector [96]. In this work a range of $40-50 \%$ of the detected ion events were multiple events, consistent with literature [102], [103]. The amount can be reduced by increasing the laser power, nevertheless, this will increase the complex ion evaporation and degrade the compositional accuracy in nitrides [101].

\section{$\underline{\text { Underestimation of } N \text { and } C \text { content }}$}

An underestimation of carbon and nitrogen contents of up to 5 at. $\%$ in carbides and in some nitride materials when using APT has been reported in literature [61], [102]. The carbon deficiency was suggested to be strongly correlated with the detector dead time, the chemical bond and the carbon sites in the carbide lattice [102], which is similar in some nitrides, e.g. $w$-AIN [61]. Additionally, an overlap between complex and single carbon (nitrogen) isotope ion peaks contribute to the underestimation, e.g. $\mathrm{C}_{2}{ }^{+}, \mathrm{C}_{4}{ }^{2+}$ and $\mathrm{Ti}^{2+}$, or $\mathrm{N}^{+}$and $\mathrm{N}_{2}{ }^{+2}$. The $\mathrm{N}$ and $\mathrm{C}$ deficiency in the total composition of a given volume (not the spatial information) can be corrected in some cases by using isolated isotopes (if they are resolved in the mass spectrum) and calculating the concentration of the other 
isotopes from the natural abundance [102], e.g. by using ${ }^{13} \mathrm{C}$ for calculating ${ }^{12} \mathrm{C}$ or ${ }^{14.5} \mathrm{~N}_{2}{ }^{2+}$ to calculate the overlap between ${ }^{14} \mathrm{~N}^{+}$and ${ }^{14} \mathrm{~N}_{2}{ }^{2+}$. Cross-validation of compositional measurements with other techniques can also be of great help.

For an unambiguous interpretation and reconstruction of the APT data, it is important to use other techniques to adjust the reconstruction parameters and to validate the observations. SEM images before and after running an APT tip are of great help and a preceding characterization of the sample with other techniques like XRD, SEM, TEM is highly recommended.

\subsubsection{Sample preparation}

All APT tips in this thesis were prepared by a FIB-based wedge lift-out technique [85]. Due to the presence of compressive stress in the films, an additional rectangular cut around the region of interest was performed. This way, a release of stress is obtained and issues regarding bending fracture during lift-out are avoided.

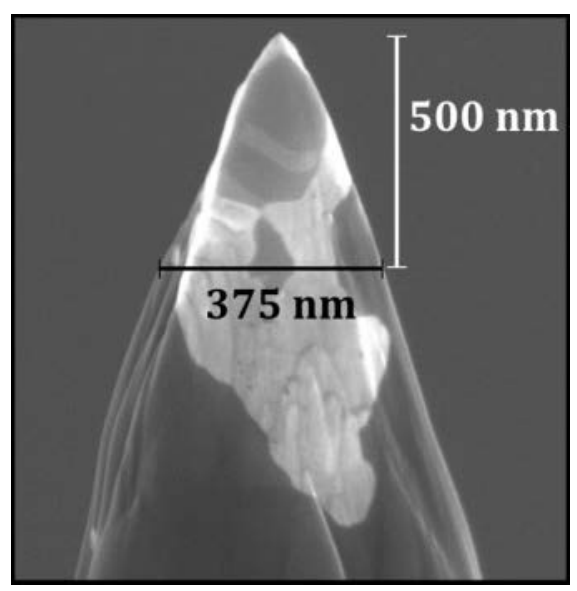

Figure 4.7: SEM image of an atom probe tip. Tilted view $\left(52^{\circ}\right)$.

The main requirements of an APT tip is a radius of 50 to $100 \mathrm{~nm}$, smooth surface (free of cracks, grooves or protrusions) and an appropriate shank angle [96]. The majority of 
the APT tips measured in this thesis fulfilled these requirements and were produced with a large shank angle, e.g. at a depth of $500 \mathrm{~nm}$ from the tip, a diameter of 350 - $400 \mathrm{~nm}$ was typically obtained (Figure 4.7). This was found to be most suitable for minimizing thermal tails and increasing the quality of the mass-to-charge spectrum (Figure 4.6).

\subsubsection{APT measurement}

APT measurements in this thesis were performed using a local electrode atom probe (Cameca LEAP 3000 X HR) in laser mode (10 ps pulse length, $532 \mathrm{~nm}$ wavelength), an evaporation rate of 5 atoms per 1000 pulses, and a laser repetition frequency of $200 \mathrm{kHz}$ with a pulse energy of $0.5 \mathrm{~nJ}$. The cryostat temperature was set to $60 \mathrm{~K}$ (base temperature). The detection efficiency of this instrument is of $37 \%$ [96].

Data reconstruction was carried out with the commercial software package IVAS (version 3.6.8, Cameca) using voltage-based tip shape reconstruction. The reconstruction parameters such as evaporation field and the geometry factor $\left(k_{f}\right)$ accounting for tip shape were obtained from the mass spectrum using Kingham curves [98] in combination with SEM images before and after run from which the length of the reconstructed tip could be estimated. A fixed image compression factor of 1.65 was used. For the majority of the $c-(\mathrm{Ti}, \mathrm{Al}) \mathrm{N}$ samples an evaporation field of $40 \mathrm{~V} / \mathrm{nm}$ was obtained (consistent with literature [103]). $k_{f}$ was set from 3.3 to 4.1 individually for each tip due to varying tip shank angles. 


\subsubsection{Visualization and data analysis}

The most common data analysis and visualizations tools used in this thesis are presented in the following:

\section{$\underline{1 D \text { concentration profiles }}$}

Composition in APT is measured from the proportion of ions/atoms of each species in a volume (voxel). Therefore, a 1D profile is a plot of the composition along a volume also called region of interest (ROI) which can have a cuboid, sphere or cylinder shape. The ROI is divided into voxels with either a fixed amount of counts (ions) or a fixed volume from which the composition is calculated and plotted in a $1 \mathrm{D}$ concentration profile. Only statistical variations are considered in the uncertainty (error bar).

A critical step when calculating 1D concentration profiles is the selection of the voxel size. If it is too small, then the statistic will be low and it can even contain no ion counts. If the voxel is too large, fine details or composition fluctuations may be lost from the analysis. The selection of the voxel size involves a balance between positional error and statistical error.

\section{$\underline{\text { Iso-concentration surfaces }}$}

An iso-concentration surface (isosurfaces) is a $3 \mathrm{D}$ visualization of an element distribution within the reconstructed tip. The analysis tool is based on isolating blocks with a specific composition (or ion density) and connecting them to a 3D surface within the reconstructed volume [96]. This helps to identify different phases, grain boundaries, precipitates and microstructure morphologies within the tip (Figure $4.8(\mathrm{a}, \mathrm{b})$ ). Isosurfaces have no physical meaning, but are helpful for visualization or as a reference point for a proximity histogram calculation. 


\section{Proximity histograms}

A proximity histogram (proxigram) is an algorithm that calculates a composition profile in 3D relative to a reference surface [104]. The first step is the creation of an isosurface which highlights the microstructure feature to be analyzed (Figure $4.8(\mathrm{a}, \mathrm{b})$ ). Then, the composition is examined normal to the isosurface in layers (shells) at increasing/decreasing distances (Figure 4.8 (c)), therefore no restriction in the surface geometry is imposed. Then, from each shell a concentration distribution profile (histogram) of each element present is generated. Finally, the data extracted from the histograms (average composition) is plotted as a proxigram composition profile (Figure 4.8 (d)). Proxigram have no restrictions on the surface morphology (geometry) [104]. However, it is very sensitive to the choice of the isosurface concentration used to describe the feature of interest.

(a)

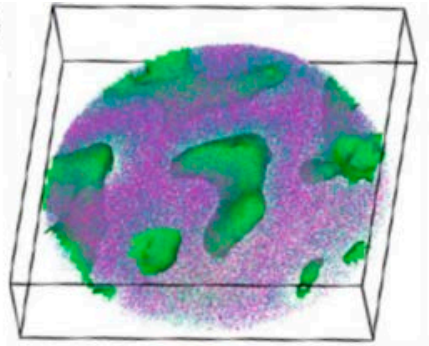

(b)

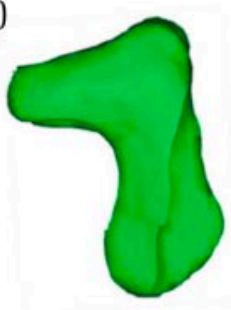

(c)

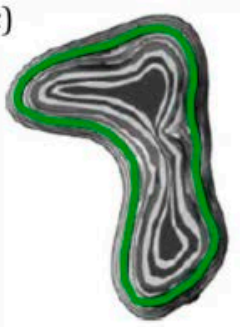

(d)

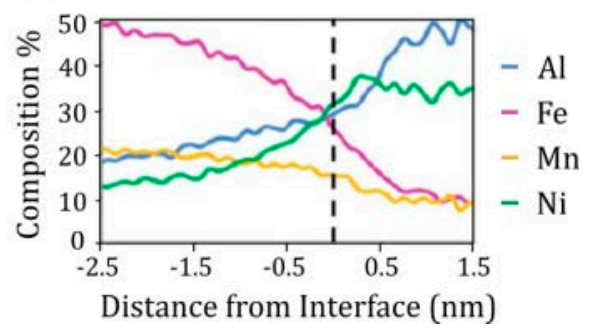

Figure 4.8: Proxigram analysis. (a) Several isoconcentration surfaces, (b) a specific surface selected for the analysis, (c) a $2 D$ illustration of how the proxigram analysis measures the average composition normal to the surface and (d) the resulting proxigram composition profile. Adapted from [96]. 


\section{Frequency distribution analysis}

A FDA is a histogram obtained by dividing an APT dataset into small volumes (voxels) containing a fixed amount of $\mathrm{n}$ ions (e.g. $\mathrm{n}>50$ ) [96]. The procedure consists in: (1) dividing the data set into small volumes (voxels), (2) extracting the composition of each voxel, (3) plotting the composition of any element present (e.g. Ti, Al, N) or any desired ratio (e.g. $\mathrm{Al}$ metallic ratio, $\mathrm{Al} /(\mathrm{Ti}+\mathrm{Al})$ ). The selection of the number of ions per voxel is a critical step in FDA. Optimized voxels are needed to minimize convolution effects, since the amplitude of the measured compositional fluctuations (especially for spinodal decomposition) depend on the voxel dimension and the amount of ions per voxel [105].

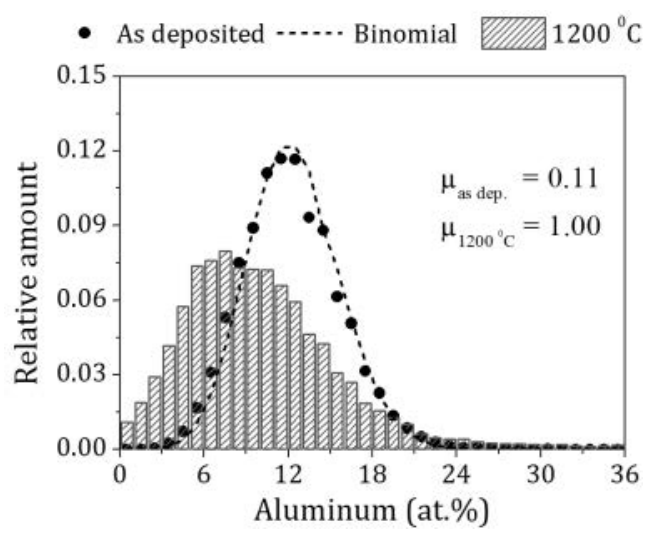

Figure 4.9: Aluminum composition histogram of as-deposited and $1200{ }^{\circ} \mathrm{C}$ annealed $\left(\right.$ Ti $\left._{0.74} A l_{0.26}\right) N_{0.82}$. Calculated random distribution (binomial) is shown for comparison. Pearson coefficient of both measured distributions is given, where 0 indicates random distribution and 1 complete segregation [61].

Histograms were normalized to the total number of voxels of each analyzed volume for comparison purposes. For visual comparison, a random discrete distribution (binomial distribution) was calculated by using the average composition of the analyzed volume. An example of an Al composition histogram from this work with its corresponding binomial distribution of an as-deposited sample and after annealing at $1200{ }^{\circ} \mathrm{C}$ is shown in Figure 4.9 [61]. 


\section{$\underline{\text { Pearson coefficient }}$}

The Pearson coefficient $(\mu)$ is a qualitative indicator of the deviation of a measured chemical composition distribution (histogram) from a binomial (random) distribution. In order to calculate $\mu$, the average composition of the volume analyzed, the total number of voxels and the measured composition histogram are needed. Pearson coefficient is calculated using the chi square statistics, $\chi_{e}^{2}$, and normalized by the total number of voxels [96], [106]. It ranges from 0 to 1 , where 0 indicates a random distribution and 1 complete segregation. $\mu$ is a qualitative indicator of segregation, since it does not distinguish between different levels and morphologies of segregation. In this study, it was interesting for the as-deposited $(\mathrm{Ti}, \mathrm{Al}) \mathrm{N}_{\mathrm{y}}$ samples since chemical fluctuations can be investigated (paper I and II). 


\section{SUMMARY OF RESULTS}

In this chapter, a summary of the most relevant results of this thesis is presented. Taken together, this work contributes mainly to the understanding of the effect of point defects on the phase transformations in cubic $(\mathrm{Ti}, \mathrm{Al}) \mathrm{N}$ alloys. It experimentally confirms theoretical predictions by Alling et al. on the effect of $\mathrm{N}$ vacancies on the decomposition pathway in $c-(\mathrm{Ti}, \mathrm{Al}) \mathrm{N}_{\mathrm{y}}(\mathrm{y}<1)$ [62]. Furthermore, this work increases the understanding of the predicted mechanism behind the early decomposition onset of (Ti,Al)N/TiN multilayers by surface-directed spinodal decomposition. The specific contributions to the field are presented in greater detail below.

\section{Paper I. Impact of nitrogen vacancies on the high temperature behavior of $\left(T i_{1-x} A l_{x}\right) N_{y}$ alloys}

This is the first study of the thermal response and structural evolution in nitrogen deficient cubic solid solution $\left(\mathrm{Ti}_{1-\mathrm{x}} \mathrm{Al}_{\mathrm{x}}\right) \mathrm{N}_{\mathrm{y}}(\mathrm{y}<1)$ thin films for different $\mathrm{Al}$ metal ratios $(\mathrm{x}=0.26,0.48$ and 0.60$)$ and $\mathrm{N}$ deficiency from $\mathrm{y}=0.92$ to 0.75 . In order to reduce complexity, free-standing coatings were used in this investigation. The results show a substantial improvement of the thermal stability by reducing the nitrogen content for alloys with a $\mathrm{Al}$ metal fractions of $\mathrm{x}=0.48$ and 0.60 . Alloys with $\mathrm{x}=0.28$ presented nucleation and growth of Al-Ti clusters inside the grains and $w$-AlN formation at grain boundaries. The decomposition paths shown in this study are consistent (with minor deviations) with predictions performed by Alling et al. on $c-(\mathrm{Ti}, \mathrm{Al}) \mathrm{N}_{\mathrm{y}}(\mathrm{y}<1)$ via static $a b$ initio calculations [62].

The nitrogen deficiency is mainly accommodated through $\mathrm{N}$ vacancies in the $c-\left(\mathrm{Ti}_{1-\mathrm{x}} \mathrm{Al}_{\mathrm{x}}\right) \mathrm{N}_{\mathrm{y}}$ phase in as-deposited thin films. At elevated temperatures, alloys with Al metal fraction $\mathrm{x}=0.48$ and 0.60 show spinodal decomposition into $c$ - $\mathrm{AlN}$ and $c$-TiN 
which is delayed with increasing $\mathrm{N}$ deficiency (Figure 5.1). As a consequence, the detrimental transformation of $c$-AlN into $w$-AlN is shifted to higher temperatures. It is suggested that the mixing energy of the system is reduced by the presence of $\mathrm{N}$ vacancies, due to a reduction of the mixing enthalpy and an alteration of the entropy. Collectively, this reduces the miscibility gap and brings the spinodal line to lower temperatures.

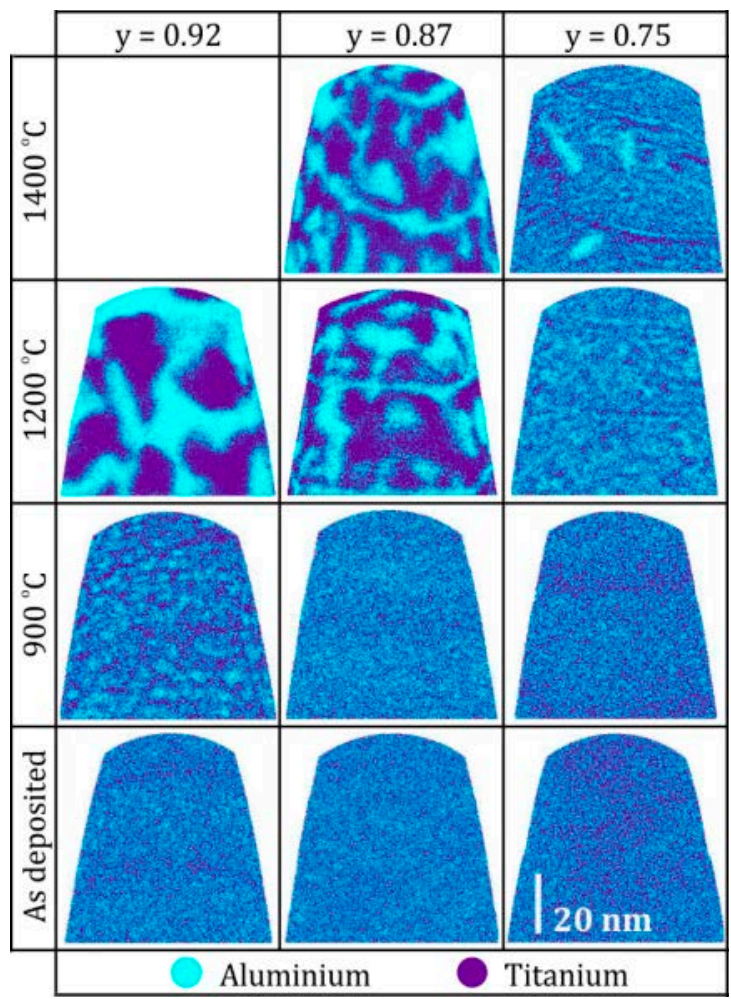

Figure 5.1: Reconstructed 3D APT tips of $\left(T_{0.52} A l_{0.48}\right) N_{y}$, with $y=0.92,0.87$ and 0.75 , in their as deposited state, and after heat treatments at $900{ }^{\circ} \mathrm{C}, 1200{ }^{\circ} \mathrm{C}$ and $1400{ }^{\circ} \mathrm{C}$. Tips were extracted from single grains and no grain boundaries are present. Only $\mathrm{Al}$ and Ti ions are presented for clarity [61].

In addition, the suppressed spinodal decomposition leads to a concurrent phase separation into $c$-TiN and $w$-AlN via nucleation and growth. This happens preferably 
along grain boundaries at high temperatures and even inside the grains at high vacancy concentrations $(\mathrm{y}=0.75)$. The positive impact of $\mathrm{N}$ vacancies led to further studies on the potential application as hard coatings in cutting tools.

\section{Paper II. Solid state formation of $\mathrm{Ti}_{4} \mathrm{AlN}_{3}$ in cathodic arc evaporated $\left(T i_{1-x} A l_{x}\right) N_{y}$ alloys}

As a complement to the first paper, the decomposition pathway in highly nitrogen-deficient solid solution cubic $\left(\mathrm{Ti}_{1-\mathrm{x}} \mathrm{Al}_{\mathrm{x}}\right) \mathrm{N}_{\mathrm{y}}(0.58 \geq \mathrm{y} \geq 0.40)$ alloys was investigated for a wide range of Al metal fractions $\mathrm{x}=0.28$ to 0.63 . This is the first study showing the formation of $\mathrm{Ti}_{4} \mathrm{AlN}_{3}$ (MAX phase) in thin films via solid state reaction in nitrogen deficient $c-\left(\mathrm{Ti}_{1-\mathrm{x}} \mathrm{Al}_{\mathrm{x}}\right) \mathrm{N}_{\mathrm{y}}$ alloys. A transformation mechanism from $\mathrm{Ti}_{2} \mathrm{AlN}$ to $\mathrm{Ti}_{4} \mathrm{AlN}_{3}$ via intercalation is suggested and it is confirmed by the presence of an intermediate $\mathrm{Ti}_{6} \mathrm{Al}_{2} \mathrm{~N}_{4}$ phase (Figure 5.2). $\mathrm{Ti}_{6} \mathrm{Al}_{2} \mathrm{~N}_{4}$ has an intergrown structure whose unit cell consists of $\mathrm{Ti}_{2} \mathrm{AlN}$ and $\mathrm{Ti}_{4} \mathrm{AlN}_{3}$ half unit cells.

\section{Transformation mechanism from $\mathrm{Ti}_{2} \mathrm{AIN}$ to $\mathrm{Ti}_{4} \mathrm{AlN}_{3}$}

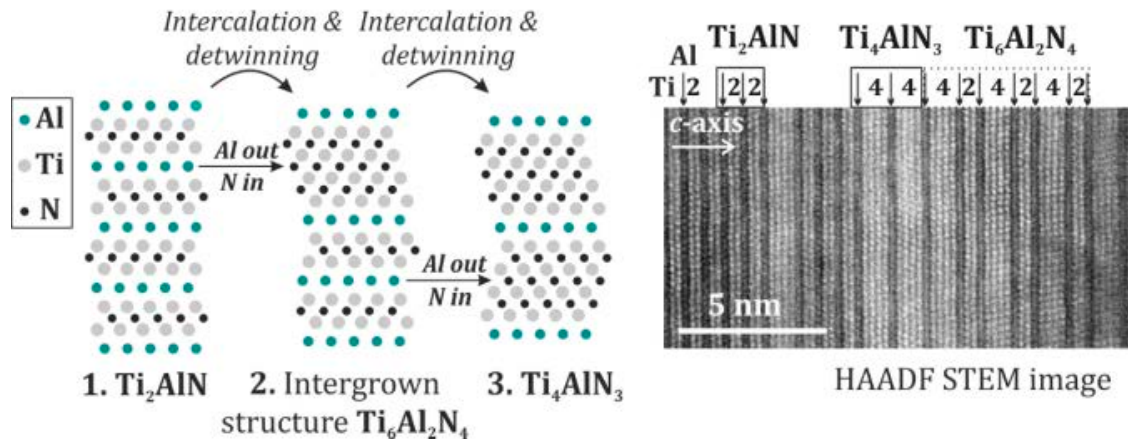

Figure 5.2: Graphical abstract [107]. (Left side) Atomic scale model of the transformation mechanism from $\mathrm{Ti}_{2} \mathrm{AlN}$ to $\mathrm{Ti}_{4} \mathrm{AlN}_{3}$ via intercalation and detwinning. (Right side) High resolution z-contrast STEM image displaying the coexistence of $\mathrm{Ti}_{2} \mathrm{AlN}$, $\mathrm{Ti}_{4} \mathrm{AlN}_{3}$, and $\mathrm{Ti}_{6} \mathrm{Al}_{2} \mathrm{~N}_{4}$ along the [1-210] direction in sample $\left(\mathrm{Ti}_{0.52} \mathrm{Al}_{0.48}\right) \mathrm{N}_{0.40}$ annealed at $1300^{\circ} \mathrm{C}$. Labels indicate the number of adjacent $N$-rich basal planes.

Highly N-deficient single-phase $c-\left(\mathrm{Ti}_{1-\mathrm{x}} \mathrm{Al}_{\mathrm{x}}\right) \mathrm{N}_{\mathrm{y}}$ thin films were grown by cathodic arc deposition for a wide composition range $(\mathrm{y}=0.40$ to 0.58 with $\mathrm{x}<0.55)$. In a first 
approach, free-standing thin films and heat treatments under Ar atmosphere were used in this study. A general model of the solid state reaction path is suggested and phases such as $\mathrm{Al}_{5} \mathrm{Ti}_{2}, \mathrm{Al}_{3} \mathrm{Ti}, c-\mathrm{TiN}, w-\mathrm{AlN}, \mathrm{Ti}_{2} \mathrm{AlN}$ and $\mathrm{Ti}_{4} \mathrm{AlN}_{3}$ are present. Their quantity can be varied with the as-deposited composition of the thin film. The phases observed are consistent with predictions performed by Alling et al. on $\mathrm{N}$-poor $c$-( $\mathrm{Ti}, \mathrm{Al}) \mathrm{N}_{\mathrm{y}}$ [62] In the reaction, it is shown that the formation of $\mathrm{Ti}_{4} \mathrm{AlN}_{3}$ takes place inside the preformed $\mathrm{Ti}_{2} \mathrm{AlN}$ (MAX phase) grains by a thermally activated diffusion process above $1200{ }^{\circ} \mathrm{C}$. The $\mathrm{Ti}_{4} \mathrm{AlN}_{3}$ formation mechanism proposed is the intercalation of $\mathrm{Al}$ layers for $\mathrm{N}$ layers along $\mathrm{Ti}_{2} \mathrm{AlN}$ basal plane accompanied by a simultaneous detwinning process (Figure 5.2). This is confirmed by the presence of the intermediate $\mathrm{Ti}_{6} \mathrm{Al}_{2} \mathrm{~N}_{4}$ phase. This study extends the mechanism of intercalation to a ternary phase. In this case, the precursor is a MAX phase of a low $n$ order $\left(\mathrm{Ti}_{2} \mathrm{AlN}\right)$ and by fulfilling several conditions, a transformation to the next thermodynamically stable MAX phase with a higher $n$ order $\left(\mathrm{Ti}_{4} \mathrm{AlN}_{3}\right)$ takes place.

\section{Paper III. Effect of nitrogen vacancies on phase stability and mechanical properties of arc deposited $\left(\mathrm{Ti}_{0.52} A \mathrm{l}_{0.48}\right) \mathrm{N}_{\mathrm{y}}(\mathrm{y}<1)$ coatings}

Based on the first paper, a medium $\mathrm{Al}$ metal fraction in the $c-\left(\mathrm{Ti}_{1-\mathrm{x}} \mathrm{Al}_{\mathrm{x}}\right) \mathrm{N}_{\mathrm{y}}$ was selected $(\mathrm{x}=0.48)$, and the thermal stability in terms of $w$-AlN formation was studied for a larger N-to-metal range $0.92 \geq y \geq 0.46$. In this study, a typical cutting tool substrate (cemented carbide WC/co based) was used in order to investigate the film-substrate interaction in the presence of $\mathrm{N}$ vacancies. The results show a clear age hardening effect (due to spinodal decomposition) upshifted by $300{ }^{\circ} \mathrm{C}$ when reducing the $\mathrm{N}$ fraction in coatings with a $y \geq 0.75$ (Figure 5.3). This upshift is consistent with the enhanced thermal stability in terms of suppressing $w$-AlN formation. High $\mathrm{N}$ deficiency $(\mathrm{y}=0.46)$ in the coating leads to a change of phase evolution and a strong interaction with $\mathrm{WC}$ and $\mathrm{Co}$ at elevated temperatures. 
As deposited coatings present an increase in composition fluctuations, lattice defects and macroparticles when reducing the $\mathrm{N}$ content, which reduces the column width and changes the preferred orientation from 200 to 111 to 220 planes parallel to the substrate.

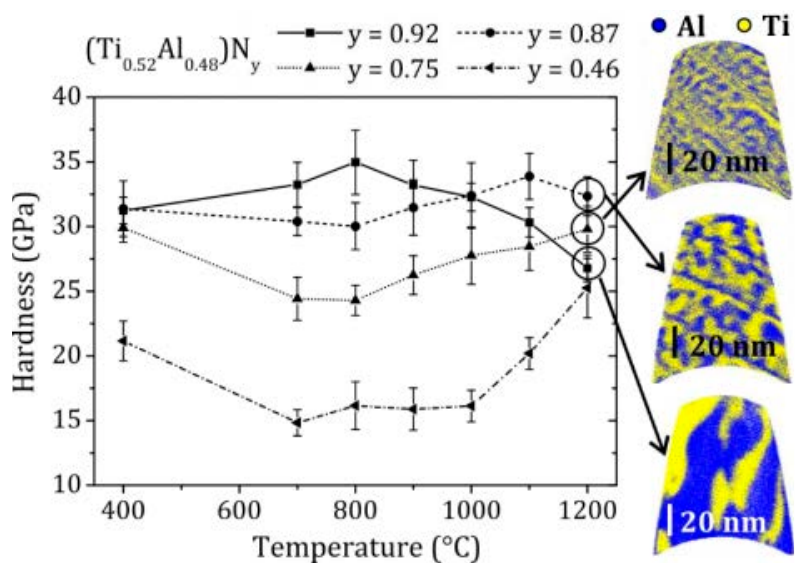

Figure 5.3: Graphical abstract [108]. Ex situ hardness versus annealing temperature up to $1200{ }^{\circ} \mathrm{C}$ of $\left(\mathrm{Ti}_{0.52} A \mathrm{l}_{0.48}\right) N_{y}$ samples with $y=0.92, y=0.87, y=0.75$ and $y=0.46 . \mathrm{APT}$ reconstructions from the interior of a column of $\left(T_{0.52} A l_{0.48}\right) N_{y}$ coatings annealed at $1200^{\circ} \mathrm{C}$ for 15 min: $y=0.92, y=0.87$, and $y=0.75$. Only Al and Ti ions are shown for clarity.

At elevated temperatures, interdiffusion of substrate elements ( $\mathrm{Co}$ and $\mathrm{C}$ ) and nucleation and growth of $c$-TiN and $w$-AlN take place mainly along column boundaries for coatings with $y \geq 0.75$. These processes seem not to be detrimental to the coatings hardness. Conversely, high $\mathrm{N}$ deficiency $(\mathrm{y}=0.46)$ leads to significant diffusion of $\mathrm{Co}, \mathrm{C}, \mathrm{W}$ and Ta throughout the coating at elevated temperatures due to the increased amount on $\mathrm{N}$ vacancies and column boundaries. Substitution of $\mathrm{N}$ by $\mathrm{C}$ in the non-metal lattice, and substitution of $\mathrm{W}$ and $\mathrm{Ta}$ in the metal lattice is observed, e.g. formation of $c-\mathrm{Ti}(\mathrm{N}, \mathrm{C}), c-(\mathrm{Ti}, \mathrm{W}, \mathrm{Ta})(\mathrm{C}, \mathrm{N})$. The overall hardness in sample $\mathrm{y}=0.46$ is lower than for coatings with $y \geq 0.75$ (Figure 5.3). Nevertheless, an increase in hardness is observed above $1000{ }^{\circ} \mathrm{C}$, and bond strengthening and solid solution hardening are suggested to be responsible for that. Base on this study, it is concluded that film-substrate interaction is a limiting factor for coating design by $\mathrm{N}$ deficiency. The most substantial improvement in hardness evolution was observed for $\mathrm{y}=0.87$. 


\section{Paper IV. Enhanced thermal stability and mechanical properties of nitrogen deficient titanium aluminum nitride $\left(\mathrm{Ti}_{0.54} \mathrm{Al}_{0.46} \mathrm{~N}_{\mathrm{y}}\right)$ thin films by tuning the applied negative bias voltage}

Base on the third paper, a fixed $\mathrm{Al}$ metal and N-to-metal fraction in the $c-\left(\mathrm{Ti}_{1-\mathrm{x}} \mathrm{Al}_{\mathrm{x}}\right) \mathrm{N}_{\mathrm{y}}$ was selected $(\mathrm{x}=0.46$ and $\mathrm{y}=0.87)$, and the effect of point defects (interstitials and anti-sites) generated during film growth was investigated in terms of phase stability and hardness. The defect density was varied by applying a negative substrate bias from -30 to $-80 \mathrm{~V}$. The results show an improvement in the as-deposited hardness for the highly biased films $(-80 \mathrm{~V})$. At elevated temperatures, the hardness behavior shows age hardening shifted to higher hardness values and to lower temperatures by increasing the negative bias (Figure 5.4). Highly bias films present an increased driving force for phase separation at elevated temperatures.

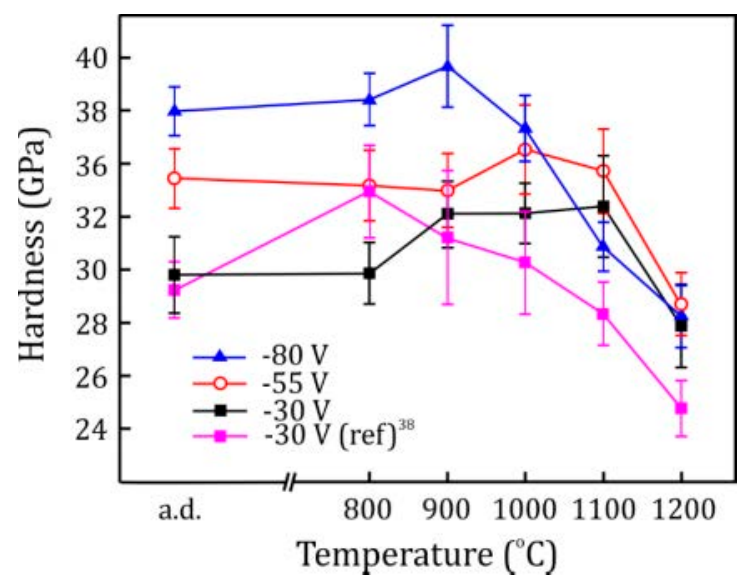

Figure 5.4: Hardness at different temperatures of $\left(\right.$ Ti $\left._{0.54} A l_{0.46}\right) N_{0.87}$ films biased at $-30 \mathrm{~V},-55 \mathrm{~V}$, and $-80 \mathrm{~V}$ and a reference sample [108] which contains a higher $N$ content $(y=0.92)[109]$.

The microstructure and the point defect density (interstitials and anti-sites) is modified in cathodic arc deposited $c$ - $\left(\mathrm{Ti}_{0.54} \mathrm{Al}_{0.46}\right) \mathrm{N}_{0.87}$ thin films by tuning the applied negative bias, since the kinetic energy of the impinging ions is altered. In the as-deposited state, films deposited with high bias $(-80 \mathrm{~V})$ show an increase in compressive stresses and 
thus in hardness due to the increase in defect density. At elevated temperatures, it is shown that the defects caused by high ion energy bombardment (high bias) are more stable in the presence of $\mathrm{N}$ vacancies than the ones generated at low energy bombardment. This effect leads to a delayed annihilation of point defects (interstitials), an increase of the system's internal energy and a retention of the hardness in high bias films (Figure 5.4). With a further increase in temperature, the release of the stored lattice strain energy in the system takes place and the decomposition of the $c$ - $\left(\mathrm{Ti}_{0.54} \mathrm{Al}_{0.46}\right) \mathrm{N}_{0.87}$ into $c$-TiN and $w$-AlN is accelerated. Thus, a shift of the age hardening effect to lower temperatures is observed (Figure 5.4). In this study, it is shown that point defect concentration generated during deposition is critical in designing $\mathrm{N}$ deficient $(\mathrm{Ti}, \mathrm{Al}) \mathrm{N}$ coatings.

\section{Paper V. Surface directed spinodal decomposition at TiAlN/TiN interfaces}

This work investigates the mechanism behind the early onset of spinodal decomposition in arc evaporated $\left(\mathrm{Ti}_{1-\mathrm{x}} \mathrm{Al}_{\mathrm{x}}\right) \mathrm{N} / \mathrm{TiN}$ multilayers, and the positive effect of artificial interfaces on the hardness. Two compositions $(x=0.50$ and 0.67$)$ were investigated in a combined study of experiments and phase-field simulations. The results show that the decomposition is initiated at the multilayer interfaces, consistent with surface-directed spinodal decomposition (SDSD) (Figure 5.5). Regardless of the composition, the same decomposition onset temperature is observed since the internal interfaces are responsible for the SDSD.

SDSD consists in the formation of a layered microstructure parallel to the interface i.e. a dominant wave vector directed normal to the surface. Phase field simulations predicted the effect of composition, internal interfaces and intrinsic composition fluctuations (induced during growth) on the microstructure and thermal stability of the multilayer system. Decomposition is initiated at the interfaces by SDSD at similar temperatures, regardless of the composition, and at earlier temperatures compared to monolithic $\left(\mathrm{Ti}_{1-\mathrm{x}} \mathrm{Al}_{\mathrm{x}}\right) \mathrm{N}$, whereas larger intrinsic fluctuations generate a more randomly oriented decomposition structure. Both mechanisms compete with each other and the resulting 
microstructure is a combination of both effects. In the case of $\left(\mathrm{Ti}_{0.34} \mathrm{Al}_{0.66}\right) \mathrm{N} / \mathrm{TiN}$ multilayers, the results show a clear SDSD at the interfaces which vanishes inside the layers due to a random decomposition (Figure 5.5). Moreover, the presence of interfaces generates coherency strains between $\mathrm{TiN}$ and $\left(\mathrm{Ti}_{1-\mathrm{x}} \mathrm{Al}_{\mathrm{x}}\right) \mathrm{N}$ due to lattice mismatch. This effect prolongs the decomposition over a longer period of time and it decreases the driving force in comparison to the monolithic layers, resulting in a prolonged age hardening.
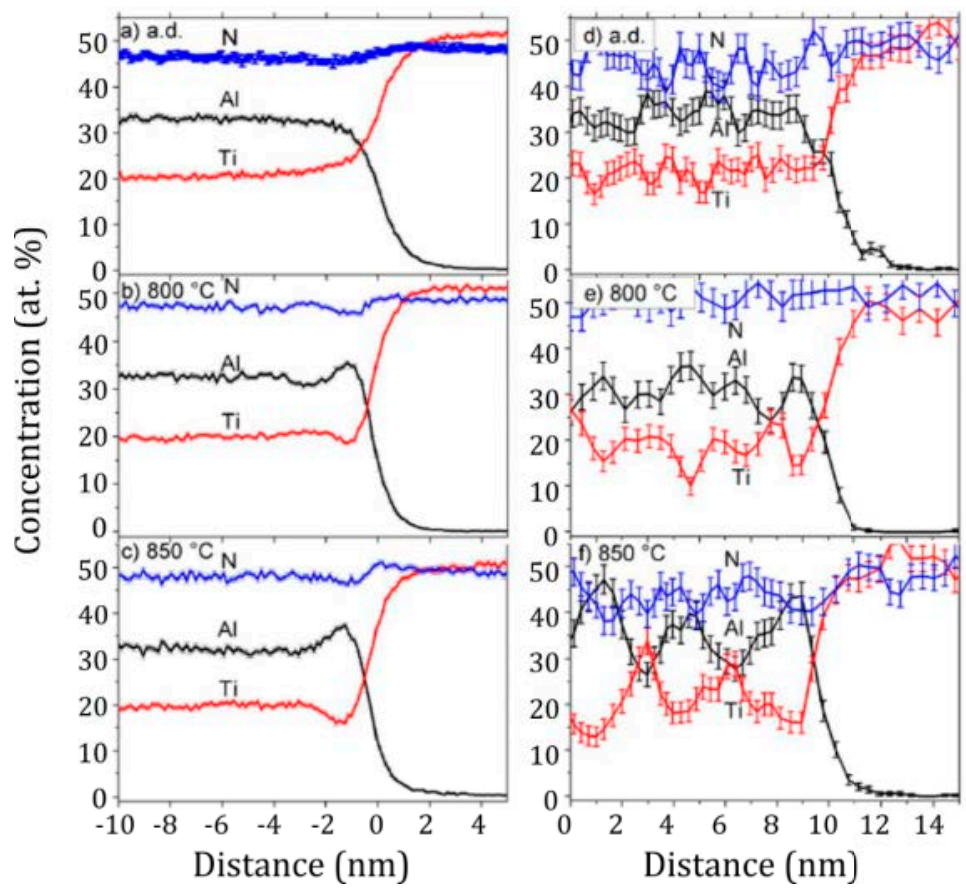

Figure 5.5: APT proxigrams from isosurfaces of a $\left(\right.$ Ti $\left._{0.34} A l_{0.66}\right) N($ left $) / T i N$ (right) multilayer interfaces in (a) as-deposited state and annealed at (b) $800^{\circ} \mathrm{C}$ and (c) $850{ }^{\circ} \mathrm{C}$, showing $\mathrm{Al}$, $T i$, and $N$. (d)-(f) show $1 D$ concentrations corresponding to a cylinder with a diameter of $5 \mathrm{~nm}$ of the same interfaces as in (a)-(c) [110]. 


\section{FUTURE WORK}

Based on the results obtained in this thesis, an outlook of possible research trends is presented in this chapter.

\section{Elastic properties and electronic structure of $(\mathrm{Ti}, A \mathrm{Al}) N_{y}(y<1)$ alloys}

It has been shown previously that spinodal decomposition, hardness and age hardening of $(\mathrm{Ti}, \mathrm{Al}) \mathrm{N}$ alloys are strongly affected by the evolving elastic properties as a function of $\mathrm{Al}$ content [18], [111] and of the $\mathrm{Al}$ distribution in the metal sublattice [112]. The increase in $\mathrm{Al}$ content increases the directional (covalent) character of the bonds, resulting in an increase in elastic anisotropy [18] and change in the electronic structure [112]. The elastic anisotropy results in a change in the nature of ( $\mathrm{Ti}, \mathrm{Al}) \mathrm{N}$ decomposition and in the resulting microstructure as pointed out by Chan [30].

In this study, it is suggested that the introduction of nitrogen vacancies in the $\mathrm{B} 1$ structure of $(\mathrm{Ti}, \mathrm{Al}) \mathrm{N}$ alloys leads to a change in bonding toward a metallic situation [61]. The results are in accordance with prediction of Alling et al. via ab initio calculations [62]. Therefore, it is expected that the elastic properties change with the $\mathrm{N}$ content. New insight into the understanding of the spinodal decomposition and age hardening in $\mathrm{N}$-deficient $(\mathrm{Ti}, \mathrm{Al}) \mathrm{N}_{\mathrm{y}}(\mathrm{y}<1)$ alloys can be obtained by the calculation of elastic properties and electronic structure.

\section{Isostructural phase diagram of cubic $(T i, A l) N_{y}(y<1)$ alloys}

Based on the results of this work, it is suggested that the enhanced thermal stability of $(\mathrm{Ti}, \mathrm{Al}) \mathrm{N}_{\mathrm{y}}(\mathrm{y}<1)$ via $\mathrm{N}$ vacancies is related to a reduction of the mixing enthalpy and an increase in the entropy. Collectively, this reduces the miscibility gap to lower 
temperatures. In order to prove this, the calculation of the isostructural phase diagram of cubic- $(\mathrm{Ti}, \mathrm{Al}) \mathrm{N}_{\mathrm{y}}$ for different $\mathrm{N}$ contents should be performed. Where vibrational contributions including anharmonicity and temperature dependence of the mixing enthalpy should also be taken into account for a good approximation. The $\mathrm{N}$ content effect on the miscibility gap will lead to a deeper understanding of the effect of $\mathrm{N}$ vacancies on thermal stability of $(\mathrm{Ti}, \mathrm{Al}) \mathrm{N}_{\mathrm{y}}(\mathrm{y}<1)$, and to the selection of an optimized $\mathrm{Al}$ metal fraction.

It is important to note, that the calculation of an isostructural phase diagram of $\mathrm{B} 1-(\mathrm{Ti}, \mathrm{Al}) \mathrm{N}_{\mathrm{y}}$ is not a trivial task since two phases must be selected, i.e. $c-\mathrm{AlN}_{\mathrm{y}}$ and $c-\mathrm{TiN}_{\mathrm{z}}$ where y and $\mathrm{z}$ must not necessarily be equal. An alternative could be the calculation of a pressure-temperature diagram of the cubic solid solution ( $\mathrm{Ti}, \mathrm{Al}) \mathrm{N}_{\mathrm{y}}$ phase.

\section{Oxidation and wear behavior in $(T i, A l) N_{y}(y<1)$}

The improved thermal stability and hardness evolution of $\mathrm{N}$-deficient $c$-(Ti,Al) $\mathrm{N}_{\mathrm{y}}$ $(y<1)$ thin films appear promising for an application as hard coating in cutting tools. In order to obtain a functional coating, further investigation of other properties must be studied such as cutting performance, wear resistance and oxidation resistance. These questions were beyond the scope of this thesis but should be investigated when considering industrial application of such coatings.

\section{Point defect engineering combined with multilayering and alloying}

As mentioned in the introduction, improving the thermal stability of $(\mathrm{Ti}, \mathrm{Al}) \mathrm{N}$ at elevated temperatures has become a key factor in hard coatings research in the last three decades. Some of the approaches were the use of multilayer configurations [2], [24], [113] or alloying elements (e.g. Cr, Hf, Ta) [23], [83], [114].

The addition of alloying elements have shown to delay the decomposition by the appearance of several intermediate phases and by changing the activation energy for 
diffusion [83], [115]. The combination of alloying and $\mathrm{N}$ vacancies could lead to an enhancement of thermal stability in $(\mathrm{Ti}, \mathrm{Al}) \mathrm{N}_{\mathrm{y}}(\mathrm{y}<1)$ alloys, since alloying elements like $\mathrm{Cr}$ or $\mathrm{Ta}$ are introduced in the metal sublattice and $\mathrm{N}$ vacancies in the non-metal sublattice.

In this study, the use of artificial interfaces by a multilayer stack (Ti,Al)N/TiN has been shown to prolong the spinodal decomposition over a longer period of time and to decrease the driving force for decomposition [110]. The generation of coherency strains due to the presence of interfaces is the main mechanism behind the enhanced age hardening. It appears interesting to explore the combined effect of artificial interfaces with $\mathrm{N}$ vacancies for a further improvement of the thermal stability and mechanical behavior of $(\mathrm{Ti}, \mathrm{Al}) \mathrm{N}_{\mathrm{y}}(\mathrm{y}<1)$ alloys.

\section{MAX phase formation via intercalation in thin films}

In this study, the mechanism of intercalation was extended to a ternary phase, where the precursor is a MAX phase of a low $n$ order which transforms into a MAX phase with a higher $n$ order, i.e. $\mathrm{Ti}_{2} \mathrm{AlN}$ into $\mathrm{Ti}_{4} \mathrm{AlN}_{3}$ [107]. In order for this transformation to take place, several conditions must be fulfilled (see paper II). According to the mechanism, the origin of the precursor MAX phase of low $n$ order is independent of transformation mechanism. It is suggested that it is possible to obtain MAX phases of high $n$ order in thin films which have not been previously obtained by direct nucleation and growth, like $\mathrm{Ti}_{4} \mathrm{GaC}_{3}, \mathrm{Nb}_{4} \mathrm{AlC}_{3}$ and $\mathrm{V}_{4} \mathrm{AlC}_{3}$. Exploring this possibility seems a promising path to continue research. 
FUTURE WORK 


\section{REFERENCES}

[1] K.-D. Bouzakis, N. Michailidis, G. Skordaris, E. Bouzakis, D. Biermann, and R. M'Saoubi, "Cutting with coated tools: Coating technologies, characterization methods and performance optimization," CIRP Ann. - Manuf. Technol., vol. 61, p. 703, 2012.

[2] S. Paldey and S. C. Deevi, "Single layer and multilayer wear resistant coatings of (Ti,Al)N: a review," Mater. Sci. Eng. A, vol. 342, p. 58, 2003.

[3] L. Hultman, "Thermal stability of nitride thin films," Vacuum, vol. 57, p. 1, 2000.

[4] M. Ohring, Materials Science of Thin Films, 2nd editio. Academic Press, 1992.

[5] D. M. Mattox, Handbook of Physical Vapor Deposition (PVD) processing. Noyes Publications, 1998.

[6] B. F. Coll, P. Sathrum, R. Fontana, J. P. Peyre, D. Duchateau, and M. Benmalek, "Optimization of arc evaporated $(\mathrm{Ti}, \mathrm{Al}) \mathrm{N}$ film composition for cutting tool applications," Surf. Coatings Technol., vol. 52, p. 57, 1992.

[7] O. Knotek, "On structure and properties of sputtered Ti and Al based hard compound films," J. Vac. Sci. Technol. A Vacuum, Surfaces, Film., vol. 4, p. 2695, 1986.

[8] H. A. Jehn, S. Hofmann, V.-E. Rückborn, and W.-D. Münz, "Morphology and properties of sputtered (Ti,Al)N layers on high speed steel substrates as a function of deposition temperature and sputtering atmosphere," J. Vac. Sci. Technol. A, vol. 4, p. 2701, 1986.

[9] S. Hofmann and H. A. Jehn, "Selective oxidation and chemical state of AL and Ti in (Ti, Al)N coatings," Surf. Interface Anal., vol. 12, p. 329, 1988.

[10] D. McIntyre, J. E. Greene, G. Håkansson, J.-E. Sundgren, and W.-D. Münz, "Oxidation of metastable single-phase polycrystalline Ti0.5Al0.5N films: Kinetics and mechanisms," J. Appl. Phys., vol. 67, p. 1542, 1990.

[11] B. Alling, A. V. Ruban, A. Karimi, L. Hultman, and I. A. Abrikosov, "Unified cluster expansion method applied to the configurational thermodynamics of cubic Ti1-xAlxN," Phys. Rev. B, vol. 83, p. 104203, Mar. 2011.

[12] N. Shulumba, O. Hellman, Z. Raza, B. Alling, J. Barrirero, F. Mücklich, I. A. Abrikosov, and M. Odén, "Lattice Vibrations Change the Solid Solubility of an Alloy at High Temperatures," Phys. Rev. Lett., vol. 117, p. 205502, 2016.

[13] P. H. Mayrhofer, A. Hörling, L. Karlsson, J. Sjölén, T. Larsson, C. Mitterer, and L. Hultman, "Self-organized nanostructures in the Ti-Al-N system," Appl. Phys. 
Lett., vol. 83, p. 2049, 2003.

[14] R. Rachbauer, S. Massl, E. Stergar, D. Holec, D. Kiener, J. Keckes, J. Patscheider, M. Stiefel, H. Leitner, and P. H. Mayrhofer, "Decomposition pathways in age hardening of Ti-Al-N films," J. Appl. Phys., vol. 110, p. 23515, 2011 .

[15] M. Odén, L. Rogström, A. Knutsson, M. R. Terner, P. Hedström, J. Almer, and J. Ilavsky, "In situ small-angle x-ray scattering study of nanostructure evolution during decomposition of arc evaporated TiAlN coatings," Appl. Phys. Lett., vol. 94, no. 5, p. 53114, 2009.

[16] P. H. Mayrhofer, A. Hörling, L. Karlsson, J. Sjölén, T. Larsson, C. Mitterer, and L. Hultman, "Self-organized nanostructures in the Ti-Al-N system," Appl. Phys. Lett., vol. 83, p. 2049, 2003.

[17] J. S. Koehler, "Attempt to design a strong solid," Phys. Rev. B, vol. 2, p. 547, 1970.

[18] F. Tasnádi, I. A. Abrikosov, L. Rogström, J. Almer, M. P. Johansson, and M. Odén, "Significant elastic anisotropy in Ti1-xAlxN alloys," Appl. Phys. Lett., vol. 97, p. 231902, 2010.

[19] A. Hörling, L. Hultman, M. Odén, J. Sjölén, and L. Karlsson, "Mechanical properties and machining performance of Ti1-xAlxN-coated cutting tools," Surf. Coatings Technol., vol. 191, p. 384, 2005.

[20] N. Norrby, L. Rogström, M. P. Johansson-Jõesaar, N. Schell, and M. Odén, "In situ X-ray scattering study of the cubic to hexagonal transformation of AlN in Ti1-xAlxN," Acta Mater., vol. 73, p. 205, 2014.

[21] O. Knotek, M. Böhmer, and T. Leyendecker, "On structure and properties of sputtered Ti and Al based hard compound films," J. Vac. Sci. Technol. A, vol. 4, p. 2695, Nov. 1986.

[22] I. A. Abrikosov, A. Knutsson, B. Alling, F. Tasnádi, H. Lind, L. Hultman, and M. Odén, "Phase stability and elasticity of TiAlN," Materials (Basel)., vol. 4, p. 1599,2011

[23] H. Lind, R. Forsén, B. Alling, N. Ghafoor, F. Tasnádi, M. P. Johansson, I. A. Abrikosov, and M. Odén, "Improving thermal stability of hard coating films via a concept of multicomponent alloying," Appl. Phys. Lett., vol. 99, no. 9, p. 91903, 2011.

[24] A. Knutsson, M. P. Johansson, L. Karlsson, and M. Odén, "Machining performance and decomposition of TiAlN/TiN multilayer coated metal cutting inserts," Surf. Coatings Technol., vol. 205, no. 16, p. 4005, May 2011.

[25] R. Rachbauer, D. Holec, and P. H. Mayrhofer, "Increased thermal stability of TiAl-N thin films by Ta alloying," Surf. Coatings Technol., vol. 211, p. 98, 2012. 
[26] N. Norrby, H. Lind, G. Parakhonskiy, M. P. Johansson, F. Tasnádi, L. S. Dubrovinsky, N. Dubrovinskaia, I. A. Abrikosov, and M. Odén, "High pressure and high temperature stabilization of cubic AlN in Ti 0.60A10.40N," J. Appl. Phys., vol. 113, p. 53515, 2013.

[27] N. Norrby, M. P. Johansson-Jõesaar, and M. Odén, "Improved metal cutting performance with bias-modulated textured Ti0.50A10.50N multilayers," Surf. Coatings Technol., vol. 257, p. 102, 2014.

[28] D. A. Porter and K. E. Easterling, Phase Transformations in Metals and Alloys, Second. Chapman \& Hall, 1992.

[29] M. Hillert, "A Theory of Nucleation for Solid Metallic Solutions," Doctoral Thesis, Massachusets Institute of Technology, 1954.

[30] J. W. Cahn, “On spinodal decomposition,” Acta Metall., vol. 9, p. 795, 1961.

[31] L. Rogström, J. Ullbrand, J. Almer, L. Hultman, B. Jansson, and M. Odén, "Strain evolution during spinodal decomposition of TiAlN thin films," Thin Solid Films, vol. 520, p. 5542, 2012.

[32] J. W. Cahn, "The later stages of spinodal decomposition and the beginnings of particle coarsening," Acta Metall., vol. 14, p. 1685, 1966.

[33] J. W. Cahn and J. E. Hilliard, "Free Energy of a Nonuniform System. I. Interfacial Free Energy," J. Chem. Phys., vol. 28, p. 258, 1958.

[34] O. Mashtalir, M. Naguib, V. N. Mochalin, Y. Dall'Agnese, M. Heon, M. W. Barsoum, and Y. Gogotsi, "Intercalation and delamination of layered carbides and carbonitrides," Nat. Commun., vol. 4, p. 1716, 2013.

[35] M. S. Dresselhaus and G. Dresselhaus, "Intercalation compounds of graphite," Adv. Phys., vol. 30, p. 139, 1981.

[36] M. J. McKelvy and W. S. Glaunsinger, "Molecular Intercalation Reactions in Lamellar Compounds," Annu. Rev. Phys. Chem., vol. 41, p. 497, 1990.

[37] P. Podsiadlo, A. K. Kaushik, A. M. Waas, B. S. Shim, J. Xu, H. Nandivada, B. G. Pumplin, J. Lahann, A. Ramamoorthy, and N. A. Kotov, "Ultrastrong and Stiff Layered Polymer Nanocomposites," Science (80-. )., vol. 318, p. 80, 2007.

[38] M. W. Barsoum, "The Mn-1AXn Phases : A New Class of Solids," Prog. Solid State Chem., vol. 28, p. 201, 2000.

[39] Y. Zhou and Z. Sun, "Crystallographic relations between Ti3SiC2 and TiC," Mater. Res. Innov., vol. 3, p. 286, 2000.

[40] D. P. Riley and E. H. Kisi, "The design of crystalline precursors for the synthesis of M n-1AXn phases and their application to Ti3AlC2," J. Am. Ceram. Soc., vol. 90, p. 2231, 2007.

[41] D. P. Riley and E. H. Kisi, "A new solid state synthesis methodology for ternary and higher order compounds," J. Aust. Ceram. Soc., vol. 43, no. 2, p. 102, 2007. 
[42] J. Emmerlich, D. Music, P. Eklund, O. Wilhelmsson, U. Jansson, J. M. Schneider, H. Högberg, and L. Hultman, "Thermal stability of Ti3SiC2 thin films," Acta Mater., vol. 55, p. 1479, 2007.

[43] H. Högberg, L. Hultman, J. Emmerlich, T. Joelsson, P. Eklund, J. M. MolinaAldareguia, J. P. Palmquist, O. Wilhelmsson, and U. Jansson, "Growth and characterization of MAX-phase thin films," Surf. Coatings Technol., vol. 193, p. 6, 2005.

[44] M. W. Barsoum and T. El-Raghy, "The MAX Phases: Unique New Carbide and Nitride Materials,” Am. Sci., vol. 89, no. 4, p. 334, 2001.

[45] M. Dahlqvist, B. Alling, and J. Rosén, "Stability trends of MAX phases from first principles," Phys. Rev. B, vol. 81, p. 230102, 2010.

[46] R. Yu, Q. Zhan, L. L. He, Y. C. Zhou, and H. Q. Ye, "Si-induced twinning of TiC and formation of Ti3SiC2 platelets," Acta Mater., vol. 50, p. 4127, 2002.

[47] S. S. Hwang, S. W. Park, and T. W. Kim, "Synthesis of the Ti3SiC2 by solid state reaction below melting temperature of Si," J. Alloys Compd., vol. 392, p. $285,2005$.

[48] A. Abdulkadhim, T. Takahashi, D. Music, F. Munnik, and J. M. Schneider, "MAX phase formation by intercalation upon annealing of $\mathrm{TiCx} / \mathrm{Al}(0.4<\mathrm{x}<1)$ bilayer thin films," Acta Mater., vol. 59, p. 6168, 2011.

[49] G. A. Slack, R. A. Tanzilli, R. O. Pohl, and J. W. Vandersande, "The intrinsic thermal conductivity of AlN," J. Phys. Chem. Solids, vol. 48, p. 641, 1987.

[50] R. Kainuma, M. Palm, and G. Inden, "Solid-phase equilibria in the Ti-rich part of the Ti-Al system," Intermetallics, vol. 2, p. 321, 1994.

[51] M. Hillert and S. Jonsson, "An Assessment of the Al-Fe-N System," Metall. Trans. A, vol. 23A, p. 3141, 1992.

[52] Q. Chen and B. Sundman, "Thermodynamic Assessment of the Ti-Al-N System," J. Phase Equilibria, vol. 19, p. 146, 1998.

[53] L. E. Toth, Transition metal carbides and nitrides. Academic Press, 1971.

[54] M. to Baben, L. Raumann, D. Music, and J. M. Schneider, "Origin of the nitrogen over- and understoichiometry in Ti0.5A10.5N thin films," J. physics. Condens. matter, vol. 24, p. 155401, 2012.

[55] A. T. Procopio, T. El-Raghy, and M. W. Barsoum, "Synthesis of Ti4AlN3 and phase equilibria in the Ti-Al-N system," Metall. Mater. Trans. A, vol. 31A, p. $373,2000$.

[56] M. A. Pietzka and J. C. Schuster, "Phase equilibria in the quarternary system TiAl-N-C," J. Am. Ceram. Soc., vol. 79, pp. 2321-2330, 1996.

[57] C. J. Rawn, M. W. Barsoum, T. El-Raghy, A. Procipio, C. M. Hoffmann, and C. R. Hubbard, "Structure of Ti4AlN3 - a layered Mn+1AXn nitride," Mater. Res. 
Bull., vol. 35, p. 1785, 2000.

[58] D. Music, R. Ahuja, and J. M. Schneider, "Theoretical study of nitrogen vacancies in Ti4AlN3," Appl. Phys. Lett., vol. 86, p. 31911, 2005.

[59] M. W. Barsoum, L. Farber, I. Levin, A. Procopio, T. El-Raghy, and A. Berner, "High-Resolution Transmission Electron Microscopy of Ti4AlN3, or Ti3Al2N2 Revisited," J. Am. Ceram. Soc., vol. 82, p. 2545, 1999.

[60] B.-Y. Shew and J.-L. Huang, "The effects of nitrogen flow on reactively sputtered Ti-Al-N films," Surf. Coatings Technol., vol. 71, p. 30, 1995.

[61] I. C. Schramm, M. P. Johansson Jõesaar, J. Jensen, F. Mücklich, and M. Odén, "Impact of nitrogen vacancies on the high temperature behavior of (Ti1-xAlx)Ny alloys," Acta Mater., vol. 119, p. 218, 2016.

[62] B. Alling, A. Karimi, L. Hultman, and I. A. Abrikosov, "First-principles study of the effect of nitrogen vacancies on the decomposition pattern in cubic Ti1-xAlxN1-y," Appl. Phys. Lett., vol. 92, no. 7, p. 71903, 2008.

[63] B. Alling, A. V. Ruban, A. Karimi, O. E. Peil, S. I. Simak, L. Hultman, and I. A. Abrikosov, "Mixing and decomposition thermodynamics of c-Ti1-xAlxN from first-principles calculations," Phys. Rev. B, vol. 75, p. 45123, Jan. 2007.

[64] Q. Xia, H. Xia, and A. L. Ruoff, "Pressure-induced rocksalt phase of aluminum nitride: A metastable structure at ambient condition," J. Appl. Phys., vol. 73, p. 8198, 1993.

[65] A. Knutsson, "Thermal stability and mechanical properties of TiAlN-based multilayer and monolithic coatings," Doctoral Thesis, Linköping University, 2012.

[66] J. Zalesak, D. Holec, I. Matko, M. Petrenec, B. Sartory, N. Koutná, R. Daniel, R. Pitonak, and J. Keckes, "Peculiarity of self-assembled cubic nanolamellae in the TiN/AIN system: Epitaxial self-stabilization by element deficiency/excess," Acta Mater., vol. 131, p. 391, 2017.

[67] C.-S. Shin, D. Gall, N. Hellgren, J. Patscheider, I. Petrov, and J. E. Greene, "Vacancy hardening in single-crystal TiNx(001) layers," J. Appl. Phys., vol. 93, p. 6025, 2003.

[68] M. Birkholz, Thin Film Analysis by X-ray Scattering. Wiley-VCH Verlag GmbH \& Co. KGaA, 2006.

[69] R. F. Bunshah, "Vapor Deposition Technologies," in Haandbook of Hard Coatings, R. F. Bunshah, Ed. Noyes Publications/William Andrew Publishing, 2001.

[70] H. Randhawa, "Cathodic arc plasma deposition technology," Thin Solid Films, vol. 167, p. $175,1988$.

[71] D. M. Sanders and A. Anders, "Review of cathodic arc deposition technology at 
the start of the new millennium," Surf. Coatings Technol., vol. 133-134, p. 78, 2000 .

[72] L. Karlsson, L. Hultman, M. P. Johansson, J.-E. Sundgren, and H. Ljungcrantz, "Growth, microstructure, and mechanical properties of arc evaporated TiCxN1-x $(0 \leq \mathrm{x} \leq 1)$ films," Surf. Coatings Technol., vol. 126, p. 1, 2000.

[73] A. Hörling, L. Hultman, M. Odén, J. Sjölén, and L. Karlsson, “Thermal stability of arc evaporated high aluminum-content Til-xAlxN thin films," J. Vac. Sci. Technol. A, vol. 20, p. 1815, 2002.

[74] I. Zhirkov, A. Petruhins, and J. Rosen, "Effect of cathode composition and nitrogen pressure on macroparticle generation and type of arc discharge in a DC arc source with Ti-Al compound cathodes," Surf. Coatings Technol., vol. 281, p. 20, 2015.

[75] A. Anders, "Energetic deposition using filtered cathodic arc plasmas," Vacuum, vol. 67, p. $673,2002$.

[76] H. Oettel, R. Wiedemann, and S. Preißler, "Residual stresses in nitride hard coatings prepared by magnetron sputtering and arc evaporation," Surf. Coatings Technol., vol. 74-75, p. 273, 1995.

[77] S. J. Bull, P. C. Evans, and A. S. Saleh, "Positron annihilation studies of defects in PVD TiN coatings," Surf. Coatings Technol., vol. 78, p. 42, 1996.

[78] M. Ahlgren and H. Blomqvist, "Influence of bias variation on residual stress and texture in TiAlN PVD coatings," Surf. Coatings Technol., vol. 200, p. 157, 2005.

[79] P. . Barna and M. Adamik, "Fundamental structure forming phenomena of polycrystalline films and the structure zone models," Thin Solid Films, vol. 317, p. 27, 1998.

[80] I. Petrov, P. B. Barna, L. Hultman, and J. E. Greene, "Microstructural evolution during film growth,” J. Vac. Sci. Technol. A, vol. 21, p. S117, 2003.

[81] L. Hultman and J. E. Sundgren, "Structure / Property Relationships For Hard Coatings," in Handbook of Hard Coatings, R. F. Bunshah, Ed. Noyes Publications/William Andrew Publishing, 2001.

[82] G. W. H. Höhne, W. Hemminger, and H.-J. Flammersheim, Differential Scanning Calorimetry. Springer Berlin Heidelberg, 2003.

[83] R. Forsén, M. Johansson, M. Odén, and N. Ghafoor, "Decomposition and phase transformation in TiCrAlN thin coatings," J. Vac. Sci. Technol. A, vol. 30, no. 6, p. 61506, 2012.

[84] R. M. Langford and M. Rogers, "In situ lift-out: Steps to improve yield and a comparison with other FIB TEM sample preparation techniques," Micron, vol. 39, p. 1325, 2008.

[85] K. Thompson, D. Lawrence, D. J. Larson, J. D. Olson, T. F. Kelly, and B. 
Gorman, "In situ site-specific specimen preparation for atom probe tomography," Ultramicroscopy, vol. 107, p. 131, 2007.

[86] W. C. Oliver and G. M. Pharr, "An improved technique for determining hardness and elastic modulus using load and displacement sensing indentation experiments," J. Mater. Res., vol. 7, p. 1564, 1992.

[87] H. J. Whitlow, G. Possnert, and C. S. Petersson, "Quantitative mass and energy dispersive elastic recoil spectrometry: Resolution and efficiency considerations," Nucl. Instruments Methods Phys. Res. Sect. B, vol. 27, p. 448, 1987.

[88] M. S. Janson, CONTES: Conversion of Time-Energy Spectra, a program for ERDA data analysis. Internal Report, Uppsala University, 2004.

[89] E. Cadel, F. Vurpillot, R. Lardé, S. Duguay, and B. Deconihout, "Depth resolution function of the laser assisted tomographic atom probe in the investigation of semiconductors," J. Appl. Phys., vol. 106, p. 44908, 2009.

[90] B. Gault, M. P. Moody, F. De Geuser, D. Haley, L. T. Stephenson, and S. P. Ringer, "Origin of the spatial resolution in atom probe microscopy," Appl. Phys. Lett., vol. 95, p. 34103, 2009.

[91] T. J. Prosa, R. A. Alvis, and T. F. Kelly, "Observations of Cluster Ions Originating from Non-Traditional Atom Probe Materials," Microsc. Microanal., vol. 14, no. Suppl 2, p. 1236, 2008.

[92] T. F. Kelly, O. Nishikawa, J. A. Panitz, and T. J. Prosa, "Prospects for Nanobiology with Atom-Probe Tomography," Mater. Res. Bull., vol. 34, p. 744, 2009.

[93] B. Gault, W. Yang, K. R. Ratinac, R. Zheng, F. Braet, and S. P. Ringer, "Atom Probe Microscopy of Self-Assembled Monolayers: Preliminary Results," Langmuir Lett., vol. 26, p. 5291, 2010.

[94] T. F. Kelly and M. K. Miller, "Invited review article: Atom probe tomography," Rev. Sci. Instrum., vol. 78, p. 31101, Mar. 2007.

[95] R. Alvis and T. F. Kelly, "Atom-Probe Microscopy LEAPs the Chasm to Mainstream Applications," Micros. Today, p. 6, 2008.

[96] B. Gault, M. P. Moody, J. M. Cairney, and S. P. Ringer, Atom Probe Microscopy, 1st ed. Springer New York, 2012.

[97] R. Gomer, Field emission and field ionization. Cambridge, Harvard Univerversity Press, 1961.

[98] D. R. Kingham, "The post-ionization of field evaporated ions: A theoretical explanation of multiple charge states," Surf. Sci. Lett., vol. 116, p. 273, 1982.

[99] P. Bas, A. Bostel, B. Deconihout, and D. Blavette, "A general protocol for the reconstruction of 3D atom probe data,” Appl. Surf. Sci., vol. 87-88, p. 298, 1995.

[100] T. T. Tsong, "Pulsed-laser-stimulated field ion emission from metal and 
semiconductor surfaces: A time-of-flight of the formation of atomic, molecular, and cluster ions," Phys. Rev. B, vol. 30, p. 4946, 1984.

[101] L. Johnson, "Inside The Miscibility Gap," Doctoral Thesis, Linköping University, 2012.

[102] M. Thuvander, J. Weidow, J. Angseryd, L. K. L. Falk, F. Liu, M. Sonestedt, K. Stiller, and H.-O. Andrén, "Quantitative atom probe analysis of carbides," Ultramicroscopy, vol. 111, p. 604, 2011.

[103] L. J. S. Johnson, M. Thuvander, K. Stiller, M. Odén, and L. Hultman, "Spinodal decomposition of Ti0.33A10.67N thin films studied by atom probe tomography," Thin Solid Films, vol. 520, p. 4362, 2012.

[104] O. C. Hellman, J. A. Vandenbroucke, J. Rüsing, D. Isheim, and D. N. Seidman, "Analysis of Three-dimensional Atom-probe Data by the Proximity Histogram," Microsc. Microanal., vol. 6, p. 437, 2000.

[105] F. Danoix, P. Auger, and D. Blavette, "Hardening of Aged Duplex Stainless Steels by Spinodal Decomposition," Microsc. Microanal., vol. 10, p. 349, 2004.

[106] K. Pearson, On the Theory of Contingency and Its Relation to Association and Normal Correlation. London: Biometric Series No. 1, Dulau and Co. Memories, 1904.

[107] I. C. Schramm, C. Pauly, M. P. Johansson Jõesaar, P. Eklund, J. Schmauch, F. Mücklich, and M. Odén, "Solid state formation of Ti4AlN3 in cathodic arc deposited (Ti1-xAlx)Ny alloys," Acta Mater., vol. 129, p. 268, 2017.

[108] I. C. Schramm, C. Pauly, M. P. J. Jõesaar, S. Slawik, S. Suarez, F. Mücklich, and M. Odén, "Effects of nitrogen vacancies on phase stability and mechanical properties of arc deposited (Ti0.52A10.48)Ny $(\mathrm{y}<1)$ coatings," Surf. Coatings Technol., vol. 330, p. 77, 2017.

[109] K. M. Calamba, I. C. Schramm, M. P. Johansson-Jõesaar, J. Ghanbaja, J. F. Pierson, F. Mücklich, and M. Odén, "Enhanced thermal stability and mechanical properties of nitrogen deficient titanium aluminum nitride (Ti0.54A10.46Ny) thin films by tuning the applied negative bias voltage," J. Appl. Phys., vol. 122, p. 65301, 2017.

[110] A. Knutsson, I. C. Schramm, K. Asp Grönhagen, F. Mücklich, and M. Odén, "Surface directed spinodal decomposition at TiAlN/TiN interfaces," J. Appl. Phys., vol. 113, p. 114305, 2013.

[111] D. J. Seol, S. Y. Hu, Y. L. Li, J. Shen, K. H. Oh, and L. Q. Chen, "Computer simulation of spinodal decomposition in constrained films," Acta Mater., vol. 51, no. 17, p. 5173, 2003.

[112] P. H. Mayrhofer, D. Music, and J. M. Schneider, "Influence of the Al distribution on the structure, elastic properties, and phase stability of supersaturated Ti1xAlxN," J. Appl. Phys., vol. 100, p. 94906, 2006. 
[113] G. B. Gaitan, J. C. Caicedo, A. G. Balogh, and S. Gottschalk, "Cutting tools performance enhancement by using a TiN/TiAlN multilayer coating system," Phys. Status Solidi Curr. Top. Solid State Phys., vol. 4, p. 4260, 2007.

[114] R. Rachbauer, A. Blutmager, D. Holec, and P. H. Mayrhofer, "Effect of Hf on structure and age hardening of Ti-Al-N thin films," Surf. Coatings Technol., vol. 206, p. 2667, 2012.

[115] R. Rachbauer, D. Holec, and P. H. Mayrhofer, "Increased thermal stability of TiAl-N thin films by Ta alloying," Surf. Coatings Technol., vol. 211, p. 98, Oct. 2012. 



\section{Papers}

The papers associated with this thesis have been removed for copyright reasons. For more details about these see:

http://urn.kb.se/resolve?urn=urn:nbn:se:liu:diva-142116 